Climate Change Economics, Vol. 9, No. 1 (2018) 1840011 (41 pages)

(C) The Author(s)

DOI: $10.1142 / \mathrm{S} 2010007818400110$

\title{
THE ROLE OF BORDER CARBON ADJUSTMENTS IN A U.S. CARBON TAX
}

\author{
WARWICK J. MCKIBBIN \\ The Australian National University, Canberra ACT 0200, Australia
}

The Brookings Institution, Washington, DC, USA

ADELE C. MORRIS

The Brookings Institution, Washington, DC, USA

amorris@brookings.edu

PETER J. WILCOXEN

Syracuse University, Syracuse, New York, USA

The Brookings Institution, Washington, DC, USA

WEIFENG LIU

The Australian National University

Canberra ACT 0200, Australia

Received 11 August 2017

Revised 22 December 2017

Accepted 3 January 2018

Published 20 March 2018

This paper examines carbon tax design options in the United States using an intertemporal computable general equilibrium model of the world economy called G-Cubed. In this paper, we discuss four policy scenarios that explore two overarching issues: (1) the effects of a carbon tax under alternative assumptions about the use of the resulting revenue, and (2) the effects of a system of import charges on carbon-intensive goods ("border carbon adjustments" or BCAs).

Consistent with earlier studies, we find that the carbon tax raises considerable revenue and reduces $\mathrm{CO}_{2}$ emissions significantly relative to baseline, no matter how the revenue is used. Gross annual revenue from the carbon tax with lump sum rebating and no BCA begins at $\$ 110$ billion in 2020 and rises gradually to $\$ 170$ billion in 2040. By 2040, annual $\mathrm{CO}_{2}$ emissions fall from 5.5 billion metric tons (BMT) under the baseline to 2.4 BMT, a decline of 3.1 BMT, or $57 \%$. Cumulative emissions over 2020 to 2040 fall by 48 BMT.

Also consistent with earlier studies, we find that the carbon tax has very small overall impacts on gross domestic product (GDP), wages, employment, and consumption. Different uses of the revenue from the carbon tax result in slightly different levels and compositions of GDP across consumption, investment and net exports. Overall, using carbon tax revenue to reduce the capital income tax rate results in better macroeconomic outcomes than using the revenue for lump sum transfers.

This is an Open Access article published by World Scientific Publishing Company. It is distributed under the terms of the Creative Commons Attribution 4.0 (CC-BY) License. Further distribution of this work is permitted, provided the original work is properly cited. 
Counter to their purported purpose of protecting U.S. trade strength, for a given revenue policy, BCAs tend to produce lower net exports than the carbon taxes alone. This is generally because the BCAs raise the value of the dollar relative to other currencies, thus lowering exports more than they lower imports. This is consistent with standard results in the international trade literature on the effects of import tariffs and export subsidies on real exchange rates, a result that is often overlooked in the discussion of domestic carbon policy.

In a finding new to the literature, our results show that BCAs can have strikingly different effects depending on the use of the revenue. Under a lump sum rebate, BCAs exacerbate the impact of the carbon tax by lowering domestic output further than it would fall under the carbon tax alone. Under a capital tax swap, however, BCAs have a moderating effect: they reduce the impact of the tax on most industries.

Keywords: Carbon tax; climate policy; border carbon adjustment; G-Cubed model.

\section{Introduction}

This paper examines carbon tax design options in the United States using an intertemporal computable general equilibrium model of the world economy called G-Cubed. It is one of a collection of papers associated with the Stanford Energy Modeling Forum 32 (EMF 32), a major multi-model analysis of a carbon tax in the United States. Detailed discussion of our results for the core policy scenarios of EMF 32 appear in Fawcett et al. (this issue). This paper examines in more detail two important design choices for a U.S. carbon tax policy: the use of the revenue, and whether and how to include measures to address the competitiveness concerns of American businesses. Both of these policy design choices affect the political appeal and overall performance of the policy, and their effects can be interdependent. For example, a carbon tax that funds reductions in corporate income tax rates could make U.S. firms more competitive overall than they otherwise might have been. Using a model of the global economy, this paper explores the effect of an illustrative carbon tax on U.S. macroeconomic outcomes with special attention to these trade-related policy design options.

The EMF 32 scenarios specify a carbon tax imposed solely in the United States. Because climate policies and effective carbon prices vary widely across countries, a unilateral carbon tax instituted in the United States could in principle promote the relocation of economic activity from the United States to regions with less ambitious climate policy, resulting in an offset to the environmental gains achieved by the United States. This is known as emissions leakage. ${ }^{1}$ Unilateral carbon pricing would be particularly likely to lower output and employment in American energy-intensive trade-exposed (EITE) sectors by hurting their global competitiveness.

On the other hand, if the United States adopts a carbon tax that slows its economic growth, that in turn may lower growth in other countries and thereby reduce their carbon emissions relative to baseline. This phenomenon is known in the literature as

\footnotetext{
${ }^{1}$ Here, we refer to the leakage that occurs through shifts in emissions-intensive industry locations. Price-based leakage occurs when fossil fuel consumption in countries without carbon constraints increases as a result of a decrease in demand and prices of traded fossil fuels. This leakage channel cannot be addressed by a border carbon adjustment or similar policy.
} 
"negative leakage." So the question arises whether, where, and in which sectors emissions leakage is positive or negative, and what the overall effect would be on global emissions. To decompose the various forces that drive leakage, this study simulates a unilateral U.S. carbon tax with G-Cubed, a computable general equilibrium model of the global economy. The global characteristics of this model make it especially well-suited to examine global spillovers of unilateral policies.

The second question we address here is the effect of measures that could counteract the potential for positive leakage and ameliorate the concerns of domestic EITE industries. $^{2}$ A number of options appear in the literature, each of which comes with important tradeoffs, ${ }^{3}$ design challenges, ${ }^{4}$ and questions of consistency with current World Trade Organization (WTO) law. ${ }^{5}$ For example, policymakers could partially or fully exempt EITE sectors from the carbon tax or give rebates to EITE firms based on their output levels. Arguably the most prominent option is a border carbon adjustment (BCA). The carbon tax itself would apply to the carbon content of imported fossil fuels, whereas a BCA would apply to goods other than fossil fuels. In practice, a BCA would apply to goods imported from countries that do not price carbon at a level at least as high as the carbon price in the United States. ${ }^{6}$ In principle, this would help ensure that the U.S. carbon tax does not disadvantage emission-intensive goods produced in the United States relative to emission-intensive goods produced in foreign countries without a similar climate policy.

A BCA on imports (which we model here) could vary by country and good, based on the average carbon intensity of production. For example, if the carbon tax in the United States is $\$ 30$ per metric ton of $\mathrm{CO}_{2}$, and steel produced in Country $\mathrm{X}$ involves emissions of five metric tons of $\mathrm{CO}_{2}$ per unit in total over the supply chain, the BCA would impose a charge of $\$ 150$ for every unit of steel the United States imports from Country $X$. The idea is that this charge would prevent unfair competition to steelmakers in the United States as a result of lower environmental standards abroad, and in principle such a charge could incentivize the exporting country to reduce its emissions. To be sure, a host of details arise, such as exactly how to calculate $\mathrm{CO}_{2}$ emissions for steel in Country $\mathrm{X}$ (for example, by firm, region, production process, or using an industry average), how to differentiate across different kinds of steel, and whether and how to account for differences between County X's policies and those of the United States.

An export BCA would rebate the carbon tax liability producers incur in making goods they export from the United States. This would help U.S. exports of emission-

\footnotetext{
${ }^{2}$ Fischer and Fox (2012a) and Condon and Ignaciuk (2013).

${ }^{3}$ For a succinct summary of these pros and cons, see Fischer et al. (2015).

${ }^{4}$ See, for example, Kortum and Wesibach (2016); CBO (2013); Sakai and Barrett (2016); Cosbey (2008); Branger and Quirion (2014) and Böhringer et al. (2012).

${ }^{5}$ For a full discussion of WTO law constraints on BCAs and similar policies, see Trachtman (2016).

${ }^{6}$ A question arises about how a BCA should apply to goods from countries that apply a carbon price at a level below that of the United States, but at a rate above zero. We abstract from that in our modeling by assuming countries either have analogous policies or no climate policy.
} 
intensive goods remain competitive in countries without similarly-stringent climate policies. Analysts generally agree that a BCA on imports would likely satisfy the requirements for an environmental exception under WTO law as long as the adjustment is no greater than the domestic carbon tax. An export BCA may be more difficult to justify in the case of a WTO dispute because its justification is trade competitiveness, not environmental protection. ${ }^{7}$ We restrict our focus here to a BCA on imports, and in our conclusions we speculate as to how our results might differ with a BCA on exports as well.

A number of studies have explored leakage and competitiveness and policy options to address them. For example, Böhringer et al. (2012) find that overall leakage rates in the range of 5-20\%. McKibbin et al. (2012a), in contrast, find no evidence of energyrelated emissions leakage.

The estimated magnitudes of the effects vary by industry as well, with EITE industries disproportionately affected (Fischer and Fox, 2012b). Aldy and Pizer (2009) estimate that vulnerable EITE industries with energy costs that exceed $10 \%$ of shipment value would expect at most a $1 \%$ shift in production overseas.

A large literature demonstrates how carbon taxes can both lower emissions and raise a substantial amount of revenue (CBO, 2011; McKibbin et al., 2012b; Rausch and Reilly, 2015). Previous literature finds that the macroeconomic impact of a carbon tax depends significantly on the use of revenue. If the revenue is used to fund reductions in other distortionary taxes, the tax reductions can offset the macroeconomic drag of the carbon tax (i.e., a weak double dividend) ${ }^{8}$ Generally, research shows that using the revenue to reduce the marginal rates of distortionary taxes such as those on capital and labor income produces better aggregate welfare than using it for lump sum rebates, although the lump sum rebates can produce more progressive distributional outcomes. ${ }^{9}$

In this paper, consistent with the EMF 32 scenario specifications, we examine a simple excise tax on the carbon content of fossil fuels in the U.S. energy sector starting in 2020 at $\$ 27$ (\$25 in \$2010) per metric ton of carbon dioxide $\left(\mathrm{CO}_{2}\right)$ and rising at 5\% above inflation each year through 2050 and remaining constant thereafter. The tax revenue either returns to households in rebates or funds reductions in the marginal tax rate on capital income, and we model both approaches with and without a BCA on imports. G-Cubed allows us to explore the possible effects of emissions control policies on: the U.S. macroeconomy; individual industrial sectors within the United States; and other outcomes, such as trade flows, currency values, emissions levels, and economic activity.

Like other studies in the EMF 32 project, our baseline and policy scenarios do not account for the economic damages that would result from a disrupted climate and thus do not capture the benefits from reducing emissions. To address this, we apply a

\footnotetext{
${ }^{7}$ Trachtman (2016).

${ }^{8}$ Goulder (1995) and Jorgenson et al. (2013).

${ }^{9}$ McKibbin et al. (2015), Tuladhar et al. (2015), Jorgenson et al. (2015) and Elmendorf (2009).
} 
marginal damage estimate from Parry et al. (2015) to each policy's reduction in emissions to obtain a first-order estimate of the benefits produced. ${ }^{10}$ By combining these estimates with our calculations of the cost of each policy we are able to report the net benefits of each tax. However, our main focus is on the relative economic outcomes of the different policy designs with equivalent environmental outcomes, consistent with the very similar cumulative emissions in our policy scenarios.

The paper is structured as follows. Section 2 describes the model, the baseline (no policy) scenario, and four policy scenarios. Section 3 reviews the results. Section 4 concludes.

\section{Modeling Approach and Scenarios}

In this section, we present a brief overview of the G-Cubed model and its features that are most relevant for our analysis. An extended technical discussion of G-Cubed appears in McKibbin and Wilcoxen (2013) and a more detailed description of the theory behind the model can be found in McKibbin and Wilcoxen (1999). ${ }^{11}$

The version of G-Cubed we use in this study includes the nine geographical regions listed in Table 1 below. The United States, Japan, Australia, and China are each represented by a separately modeled region. The model aggregates the rest of the world (ROW) into five composite regions: Western Europe, the rest of the OECD (not including Mexico and Korea); Eastern Europe and the former Soviet Union; OPEC oil exporting economies; and all other developing countries.

The full list of sectors in the model is shown in Table 2. The "code" column provides short names for the sectors that will appear in tables and graphs of results. G-Cubed's electricity sector includes specific technologies: coal, natural gas, oil,

Table 1. Regions in the G-Cubed model.

\begin{tabular}{ll}
\hline Region code & \multicolumn{1}{c}{ Region description } \\
\hline US & United States \\
Japan & Japan \\
Aus & Australia \\
Eur & Western Europe \\
ROECD & Rest of the OECD, i.e., Canada and New Zealand \\
China & China \\
EEFSU & Eastern Europe and the former Soviet Union \\
LDC & Other Developing Countries \\
OPEC & Oil Exporting Developing Countries \\
\hline
\end{tabular}

\footnotetext{
${ }^{10}$ The result is first-order in the sense that it does not capture any impacts of the reduction in emissions on production and consumption decisions.

${ }^{11}$ The type of CGE model represented by G-Cubed, with macroeconomic dynamics and various nominal rigidities, is closely related to the dynamic stochastic general equilibrium models that appear in the macroeconomic and central banking literatures.
} 
Table 2. Sectors in the G-Cubed model.

\begin{tabular}{lccc}
\hline Number & Sector name & Code & Notes \\
\hline 1 & Electricity delivery & ElecU & Primary energy \\
2 & Gas utilities & GasU & \\
3 & Petroleum refining & Ref & \\
4 & Coal mining & CoalEx & \\
5 & Crude oil extraction & CrOil & \\
6 & Natural gas extraction & GasEx & \\
7 & Other mining & Mine & Non-energy traded goods \\
8 & Agriculture and forestry & Ag & \\
9 & Durable goods & Dur & \\
10 & Non-durables & NonD & \\
11 & Transportation & Trans & \\
12 & Services & Serv & \\
13 & Coal generation & Coa & Electricity generation \\
14 & Natural gas generation & Gas & \\
15 & Petroleum generation & Oil & \\
16 & Nuclear generation & Nuc & \\
17 & Wind generation & Win & \\
18 & Solar generation & Sun & \\
19 & Hydroelectric generation & Hyd & \\
20 & Other generation & Oth & \\
\hline
\end{tabular}

nuclear, wind, solar, hydro, and others (largely biomass and other renewables). A technical discussion of modeling improvements to the electricity sector appears in McKibbin et al. (2015).

\subsection{The baseline scenario}

The model's projections of future emissions and economic activity in the absence of new climate policy is our business-as-usual (baseline) scenario. A detailed discussion of the baseline construction process for G-Cubed appears in McKibbin et al. (2009). ${ }^{12}$ Per the scenario specifications of EMF 32, the baseline in this study is broadly consistent with the emissions and gross domestic product (GDP) growth in the Energy Information Administration's Annual Energy Outlook Early Release, No Clean Power Plan case from May 2016. ${ }^{13}$ However, our projected productivity growth rates cause

\footnotetext{
${ }^{12}$ Constructing the baseline begins with population forecasts by region and recent estimates of productivity growth at the sectoral level. We then assume that productivity growth rates evolve over time in such a way that productivity levels gradually converge across countries (slowly for some countries; more rapidly for others). Because G-Cubed is relatively aggregate, we do not build in explicit assumptions about the rate of adoption of end-use technologies such as electric vehicles. We also do not include explicit limits on the adoption of renewables or nuclear power, apart from including adjustment costs to capture the fact that it is difficult to expand them quickly. Finally, this version of the model does not include any form of carbon capture and sequestration.

${ }^{13}$ The report appears at the DOE's Energy Information Administration website: https://www.eia.gov/forecasts/aeo/er/.
} 
the model's baseline to be slightly higher for both variables. We assume that annual federal deficits will start to be reined in when the Federal debt reaches 100\% of GDP. Accordingly, we impose lump sum taxes annually such that ratio of debt to GDP is no higher than one.

Along with the baseline for the United States, we construct a baseline scenario for the other regions in the world that reflects our best estimate of the likely evolution of each region's economy without concerted climate policy measures beyond those announced by the end of 2015. To generate this scenario, we begin by calibrating the model to reproduce approximately the relationship between economic growth and emissions growth in the United States and other regions over the past decade and then impose carbon policies that were already implemented as of mid-2016. In the baseline, neither the United States nor other countries adopt climate policies that are any more restrictive than is reflected in existing policies.

The greenhouse gas emissions included in G-Cubed comprise only $\mathrm{CO}_{2}$ from energy-related fossil fuel consumption, including combustion of coal, natural gas, and oil. Figure 1 shows the model's projections from 2015 to 2040 for global $\mathrm{CO}_{2}$ emissions from energy use across four major regions: China, the United States, Europe, and the ROW. These projections do not include countries' Nationally Determined Contribution pledges in the 2015 Paris Agreement. ${ }^{14}$

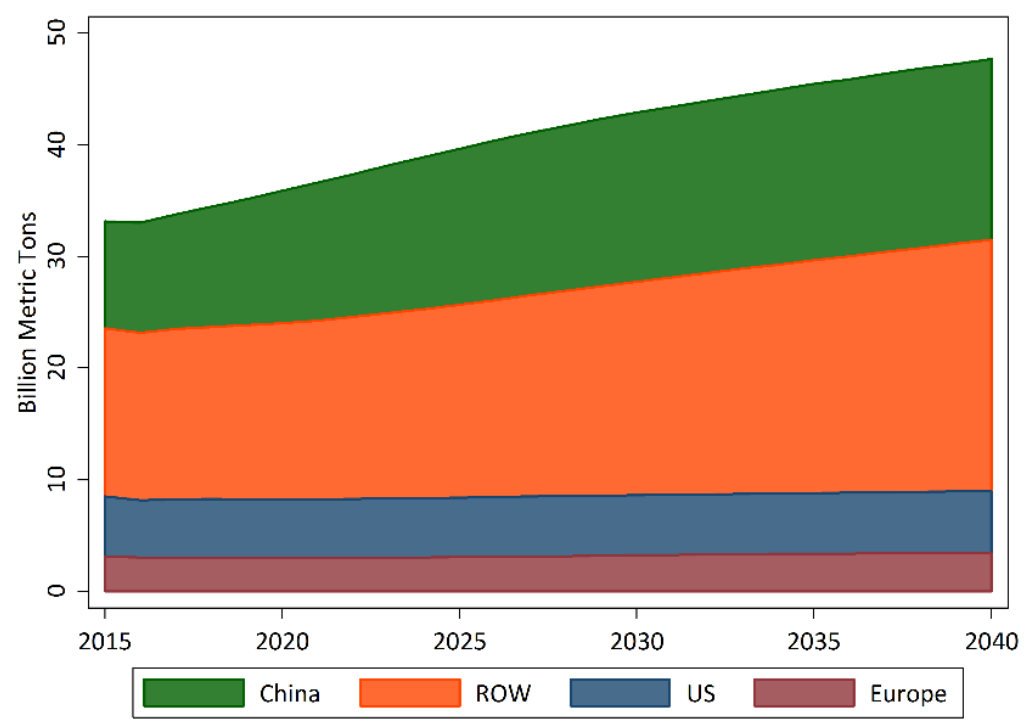

Figure 1. Global baseline carbon dioxide emissions.

\footnotetext{
${ }^{14}$ In December 2015, the Parties to the United Nations Framework Convention on Climate Change met in Paris. They struck an agreement in which 195 countries made climate-related pledges. The agreement went to force in March 2017, having been ratified by 141 nations. http://www.un.org/apps/news/story.asp?NewsID=56477\#.WScXEE0zWgz.
} 


\subsection{The policy scenarios}

In this EMF 32 study, we examine an illustrative carbon tax imposed in the United States but not in other countries. The tax applies economy-wide to all sources of $\mathrm{CO}_{2}$ emissions from fossil energy use. To the extent that trade and investment may be distorted by climate policy, those outcomes are most likely to be apparent in such a unilateral context. Thus, in our scenarios without border measures, we are likely estimating the upper bound on competitiveness effects.

As shown in Fig. $2{ }^{15}$ we impose the tax beginning in 2020, starting at $\$ 27$ (in $\$ 2015$, or $\$ 25$ in $\$ 2010$ ) per metric ton of $\mathrm{CO}_{2}$, and we increase the tax rate annually by $5 \%$ over inflation. By 2040, the final year we report for our simulations in this paper, the tax is $\$ 72$ per metric ton. In years after 2050 , which are relevant for agents in the model with forward-looking expectations, we hold the carbon tax rate constant at its 2050 level of $\$ 117$. We assume the carbon tax is anticipated, not a surprise.

We focus on two different assumptions about how the carbon tax revenue is used. ${ }^{16}$ Both of these revenue scenarios are part of the core EMF 32 scenarios. The first, denoted LS in figures and tables, assumes the revenue is returned to households each year as a lump sum rebate. The second, denoted KT, applies the revenue to reduce the marginal tax rate on capital income. In both cases the revenue is adjusted so that total government spending is constant relative to baseline.

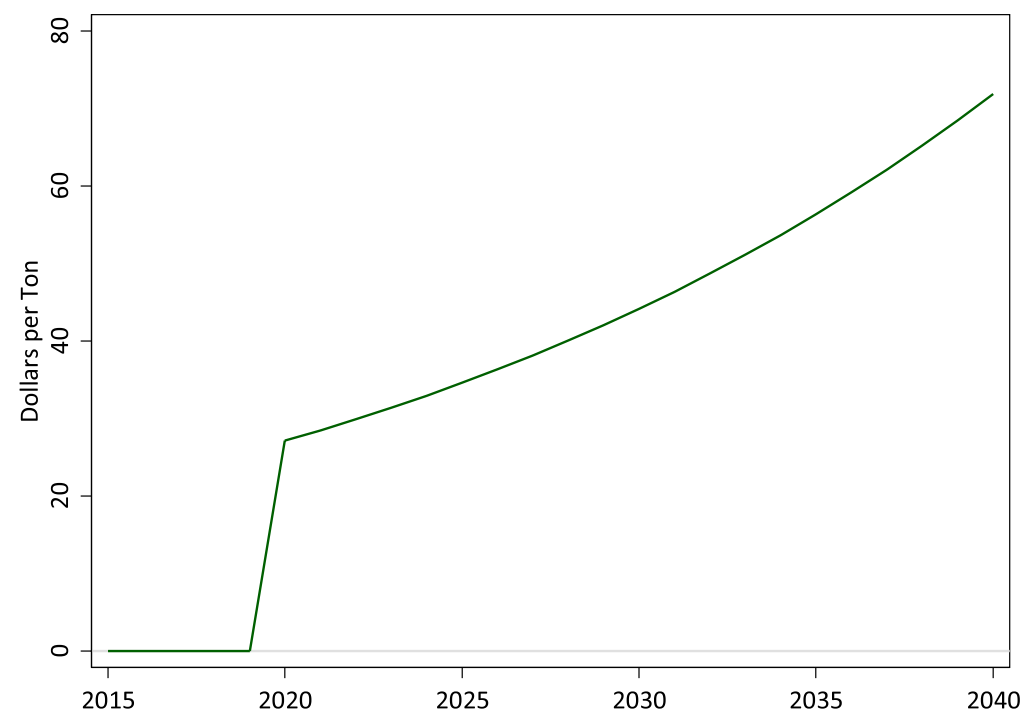

Figure 2. U.S. tax rate on $\mathrm{CO}_{2}$.

\footnotetext{
${ }^{15}$ Unless otherwise indicated, all dollar values are in 2015 dollars.

${ }^{16}$ The overview and cross cut papers in this issue also report G-cubed results for other tax trajectories and revenue scenarios.
} 
In the LS rebate scenarios, general equilibrium effects of the carbon tax lower the revenue from other taxes, so the total rebates in each year are a little smaller than the gross receipts of the carbon tax. In the tax swap scenarios, we calculate the change in the capital income tax rate (in percentage points) achievable in each period, using the recycled revenue to hold the deficit constant relative to baseline.

We also run a variation on each policy that imposes import BCAs in proportion to the carbon content of non-fuel imported goods (denoted LS BCA and KT BCA). These simulations necessarily involve making strong assumptions about how a BCA might work (no country has yet imposed one). For example, we must specify to which goods the BCA would apply, its magnitude, other countries' climate policies, and the extent to which they react (or not) to a BCA on their goods. Many combinations of carbon pricing policies and BCA designs around the world are possible. Our goal here is to choose an illustrative scenario that is a sort of boundary case, deviating only in one regard from the core EMF 32 scenarios, and glean from it insights about the economic forces the policies can induce.

Per the EMF 32 scenario specifications, we assume no new climate policies around the world, but we do account for existing climate policies. Some of the most stringent existing climate policies are in the European Union. Accordingly, in our simulation we exempt European goods from the BCA on the grounds that European carbon policies, including the European Emissions Trading System, carbon taxes, and other regulations are collectively sufficiently comparable with the tax in the U.S. that the exemption could be justified. ${ }^{17}$ When presenting our results, we will briefly discuss how they would differ if the BCA were applied to Europe as well.

A BCA is a unit tax, meaning for each unit it is the carbon emissions associated with the production of a unit of the good times the relevant carbon tax rate. The BCA does not depend on the market value of the good, so it is not equivalent to an ad valorem tariff. However, as we shall see it produces much the same effects as a specific tariff. Applying the most expansive possible implementation, we impose the BCA on all goods imported from all regions other than the E.U. As a practical matter, we are able to do so because the model's goods and regions are both highly aggregated; as Kortum and Weisbach (2017) note, following the same procedure for finely disaggregated sets of goods and regions may be infeasible. Appendix B explains how we calculate the emission intensity of each good and compute the revenue associated with the BCA. In short, we compute the carbon intensity of each broad category of traded goods in G-Cubed in each region at the outset of the policy in 2020. We then adjust the BCA over time to account for each region's baseline improvements in energy and carbon intensity. We add the revenue from the border adjustments to the direct revenue stemming from the carbon tax policy and use it in the same way, either incorporated in

\footnotetext{
${ }^{17}$ For compendia of explicit and effective carbon prices around the world, see World Bank et al. (2017) and OECD (2016).
} 
the lump sum rebate or as part of the revenue recycled via a reduction in the capital tax rate.

To be sure, we are not arguing that our scenario is the most likely or practical. Indeed, we stress that there are considerable uncertainties involved in how a BCA and carbon pricing policies more generally will play in out practice. For one, the BCA program would likely be restricted to the most carbon-intensive goods. Also, the carbon intensity of imports from different countries could evolve very differently from what we assume here if market conditions change or the countries adopt new policies. For example, the volume of trade from each region to the United States is very uncertain as it depends on overall economic growth, the evolution of comparative advantages in each country, terms of trade, and a host of other factors. In addition, other countries are likely to have climate policies (including carbon prices) of their own, and they may respond to the U.S. BCA in a variety of ways, including by obviating the U.S. BCA by taxing, at least, the carbon content of their exports. In addition, U.S. authorities may be required by trade law to allow individual firms to petition for a lower BCA if they can prove their production is lower in carbon than the national average. ${ }^{18}$

Despite these (and more) real-world considerations, our simulation, other than exempting the E.U., provides the broadest possible implementation of a BCA on imports to the U.S. and thus is likely to showcase potentially interesting economic outcomes. This sharpens the contrast between different policy options, particularly on how the impact of a BCA varies with how the revenue is used.

Table 3 below summarizes the key features of the five scenarios. The comparative general equilibrium effects of these scenarios are of particular interest. For example, the tax swap scenarios (KT and KT BCA) use the carbon tax revenue to reduce other distortions in the economy. This raises the question of whether the net effect of these fiscal reforms on employment, consumption, and GDP will be positive or negative.

Our fiscal closure is consistent with the EMF 32 scenario guidelines. Because a carbon tax policy can change wages and thus change the burden of government, as noted above

Table 3. Summary of baseline and policy scenarios.

\begin{tabular}{lcccc}
\hline Scenario & Carbon tax & Lump sum rebate & Capital tax reduction & Border adjustment \\
\hline Baseline & No & No & No & No \\
LS & Yes & Yes & No & No \\
KT & Yes & No & Yes & No \\
LS BCA & Yes & Yes & No & Yes \\
KT BCA & Yes & No & Yes & Yes \\
\hline
\end{tabular}

${ }^{18}$ Cosbey (2008), pp. 24-26. 
we hold government total real spending on everything (including interest payments) to baseline levels. We also hold the federal deficit unchanged relative to baseline levels. Together, these restrictions determine the overall level of government revenue required. After accounting for the revenue raised by the carbon tax, by the BCA if applicable, and by other taxes (such as from labor income), we adjust the lump sum rebate or the capital tax rate as needed to achieve the target level of revenue. This approach is imposed for analytical clarity and is not necessarily a practical way to implement a carbon tax.

\section{Results}

As shown in Fig. 3, the carbon tax would have an immediate and substantial impact on U.S. $\mathrm{CO}_{2}$ emissions no matter the details of the tax policy. Under the LS policy emissions fall relative to baseline by 1.14 BMT when the tax is imposed in 2020 and are 3.17 BMT lower by 2040. Emissions fall slightly less under the capital tax reduction (KT): 1.08 BMT in 2020 and 3.07 BMT in 2040. The addition of border adjustments (LS BCA and KT BCA) has almost no impact on domestic emissions. By 2040, cumulative reductions under all four of the policies are very close to each other: the results range from a low of 45 BMT under KT BCA to a high of 48 BMT under LS BCA.

Figure 4 shows the impact of each policy as a percent reduction in baseline emissions. The initial impact in 2020 is a drop of about $20-21 \%$ and by 2040 the reduction is around $53-57 \%$ depending on the policy.

One of the key motivations for a BCA system is a concern about emissions leakage. In principle, high-carbon imported goods could displace domestic production, with

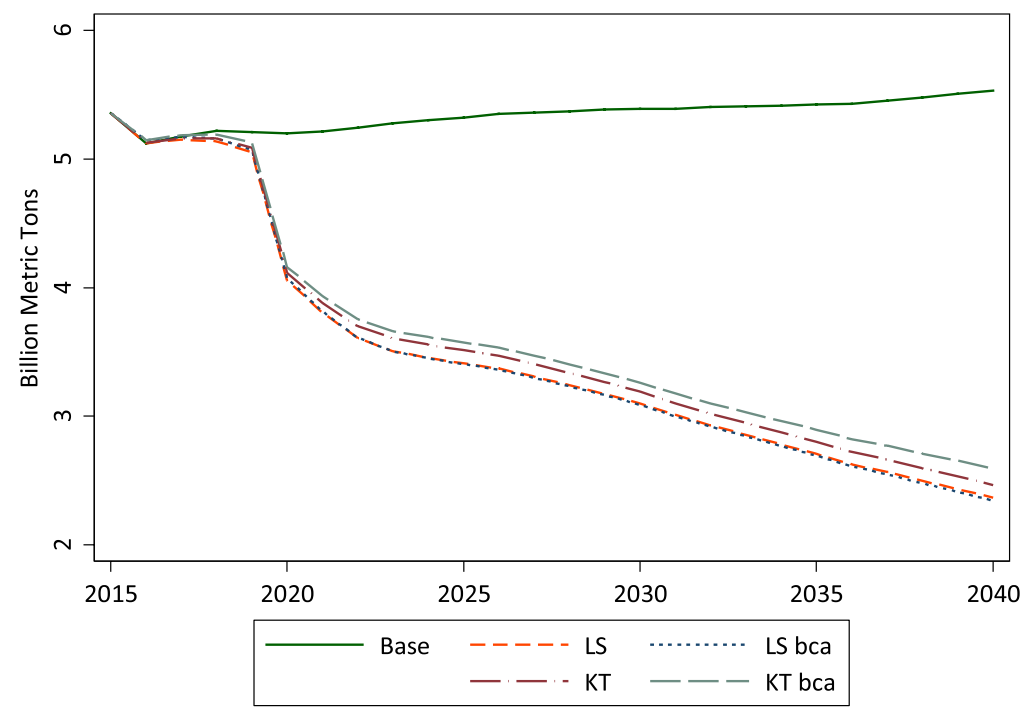

Figure 3. Level of U.S. emissions of $\mathrm{CO}_{2}$ in BMT. 


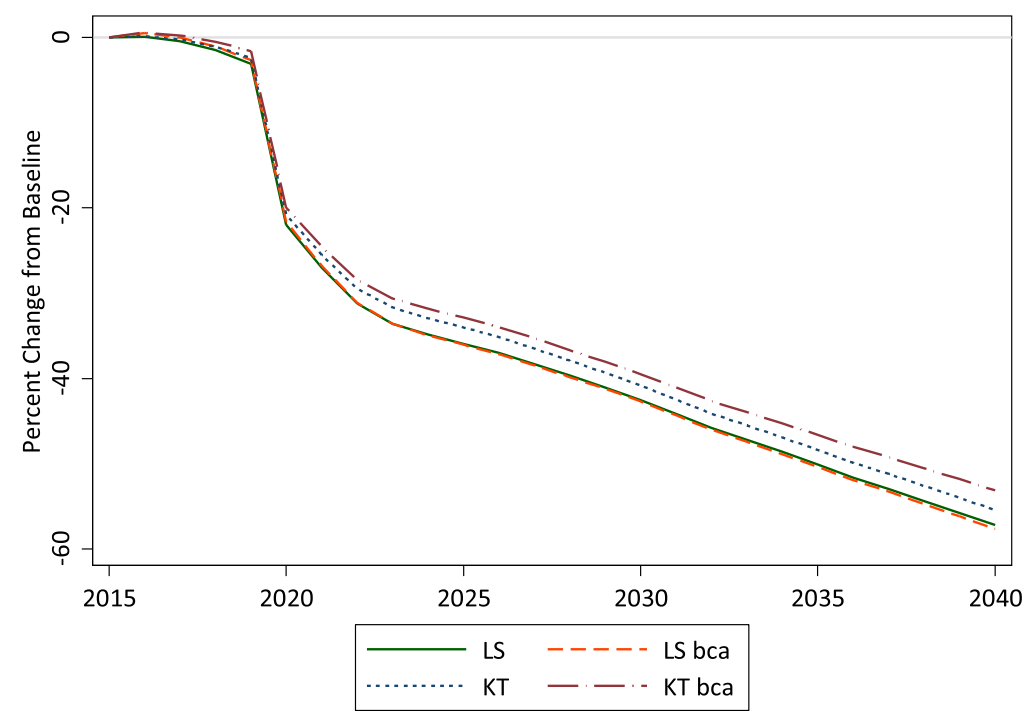

Figure 4. Changes in U.S. $\mathrm{CO}_{2}$ emissions relative to baseline.

little net benefit to the climate. Figure 5 reports global emissions relative to baseline in each of the scenarios. We find that net leakage (accounting for both positive leakage due to the tax and negative leakage due to the reduction in global demand) is very minor: the four policy curves are nearly identical at the scale of the graph. Adding a BCA to either of the tax policies does, in fact, reduce global emissions slightly more than the policy alone. However, the difference is very small relative to the overall decrease. We conclude that leakage is not an important issue with or without a BCA. ${ }^{19}$ We will return to this point later in the paper when we discuss the impact of each policy on emissions by each region.

Figure 6 shows the gross receipts of the carbon tax and the BCA in each scenario. The tax policies without BCAs generate roughly $\$ 110$ billion in the first year and rise to $\$ 170-\$ 177$ billion by 2040 . The carbon tax policies with BCAs bring in substantially more revenue, starting at about $\$ 150$ billion in 2020 and more than doubling to about $\$ 350$ billion in 2040. Had we levied the BCAs against Europe as well, revenue would be even higher. Revenue is slightly higher under the capital tax cases since emissions don't fall quite as much.

To put these figures in perspective, the revenues are shown as a percent of baseline GDP in Fig. 7. In 2020, the carbon taxes without BCAs raise revenue equivalent to about $0.5 \%$ of GDP, which is roughly similar to the total for all U.S. federal excise

\footnotetext{
${ }^{19}$ To be sure, for segments of the economy much narrower than our sectors, a BCA could be very important. An example that is often mentioned is aluminum smelting, which is tremendously energy-intensive. Our model is too aggregate to pick up impacts on industries that narrow. By the same token, however, we also apply sector-average BCAs to subsectors that are less energy-intensive than average. The first impact would lead us to underestimate the impact of a BCA on protecting U.S. producers while the latter would lead us to overestimate it. The net impact is not clear.
} 


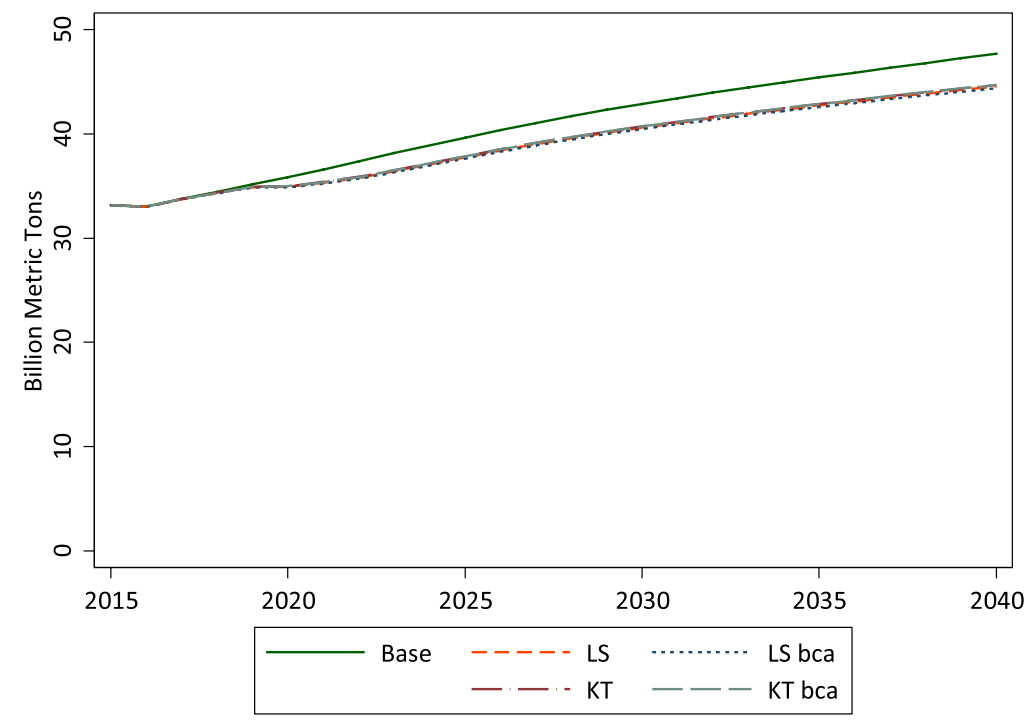

Figure 5. Changes in global $\mathrm{CO}_{2}$ emissions relative to baseline.

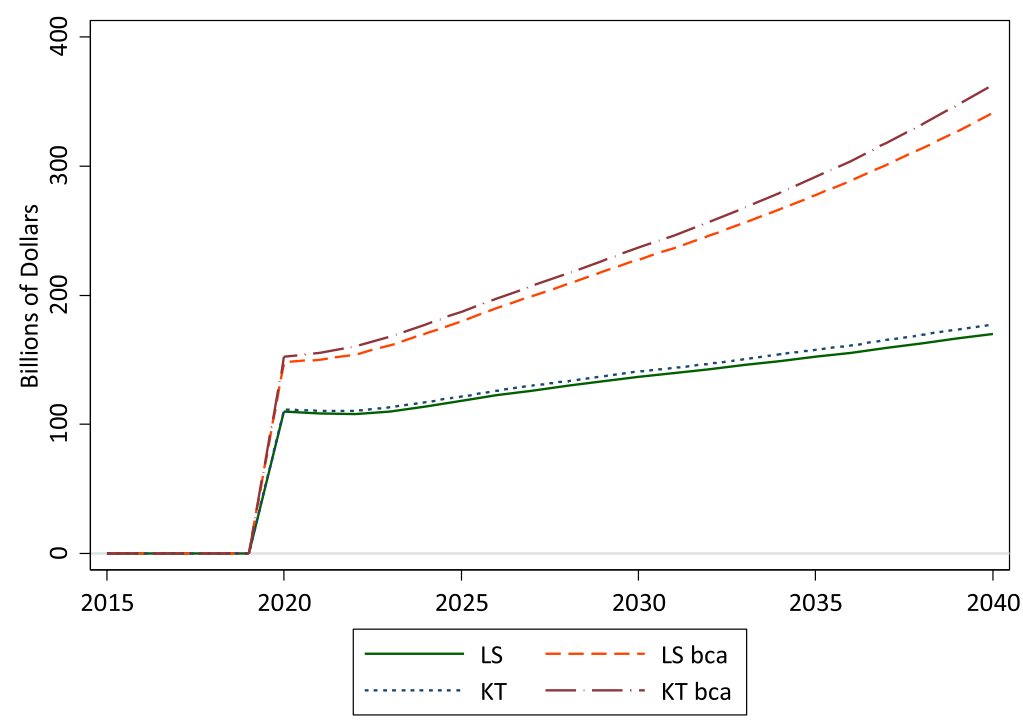

Figure 6. Gross revenue in billions of $\$ 2015$ dollars.

taxes today. ${ }^{20}$ Through 2040, the increase in the carbon tax rate approximately balances out the decline in emissions. Revenue from BCAs adds about $0.25 \%$ of GDP in 2020 and grows to about $0.6 \%$ of GDP by 2040 .

Figure 8 displays the composition of the BCAs by the regions from which goods are imported into the United States. The preponderance of the BCA revenue comes

\footnotetext{
${ }^{20}$ Peter G. Peterson Foundation, Revenue: http://www.pgpf.org/finding-solutions/understanding-the-budget/revenue.
} 


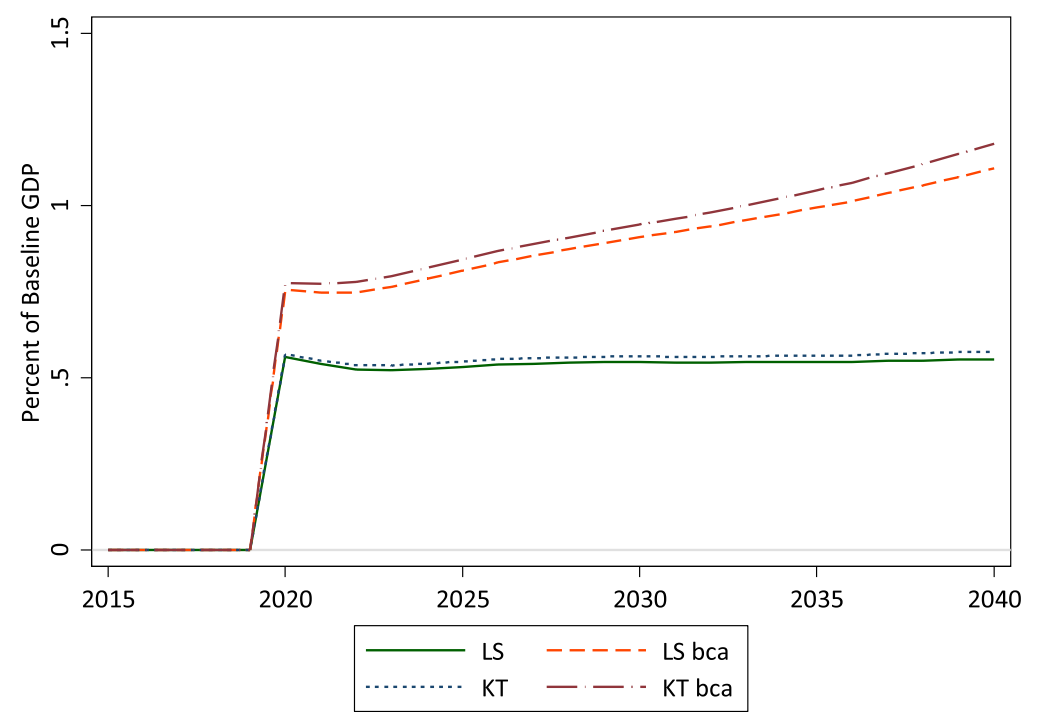

Figure 7. Gross revenue as a percent of baseline GDP.

from China and LDCs, reflecting both the carbon intensity and volume of trade with those regions. Revenue from BCAs on goods from LDCs rises relatively rapidly because our baseline assumes relatively little reduction in emissions intensity in that region.

Figure 9 shows the border adjustments used in the LS BCA and KT BCA simulations. Each bar indicates the border adjustment for a particular good from a particular country of origin in cents per model unit in 2035. The model's prices are normalized to one in 2015, so roughly speaking the adjustments range from about 1 to 8 percent. Figure 9 shows the adjustments grouped first by country and then by good, while Fig. 10 shows them grouped by good and then country. As noted above, border adjustments are only applied on the six non-fuel goods (sectors 7-12 in Table 2). Europe does not appear in either figure because no border adjustments are applied against it. In general, the border adjustments tend to be relatively high for China, the rest of the OECD, and Eastern Europe and the former Soviet Union, reflecting their relatively high 2035 projected carbon intensity. For reference, the U.S. carbon tax is approximately $\$ 56$ per ton of $\mathrm{CO}_{2}$ in 2035. At that rate, a border adjustment of 8 cents, such as that on durables from China, indicates that there is approximately $1.4 \mathrm{~kg}$ of $\mathrm{CO}_{2}$ per dollar of imports.

Before we turn to the macroeconomic outcomes of the different policy scenarios, it is worth noting the fiscal effects of the revenue uses. Figure 11 shows the trajectory of the tax rate on capital income in the KT and KT BCA scenarios. In the baseline, the tax rate stays constant at $6.47 \% .{ }^{21}$ In the KT scenario, the capital income tax rate falls by

\footnotetext{
${ }^{21}$ The model has a single tax on capital. In the baseline it is set to the overall average rate of taxation on capital income in the economy. As a result, it is considerably lower than the statutory corporate tax rate.
} 


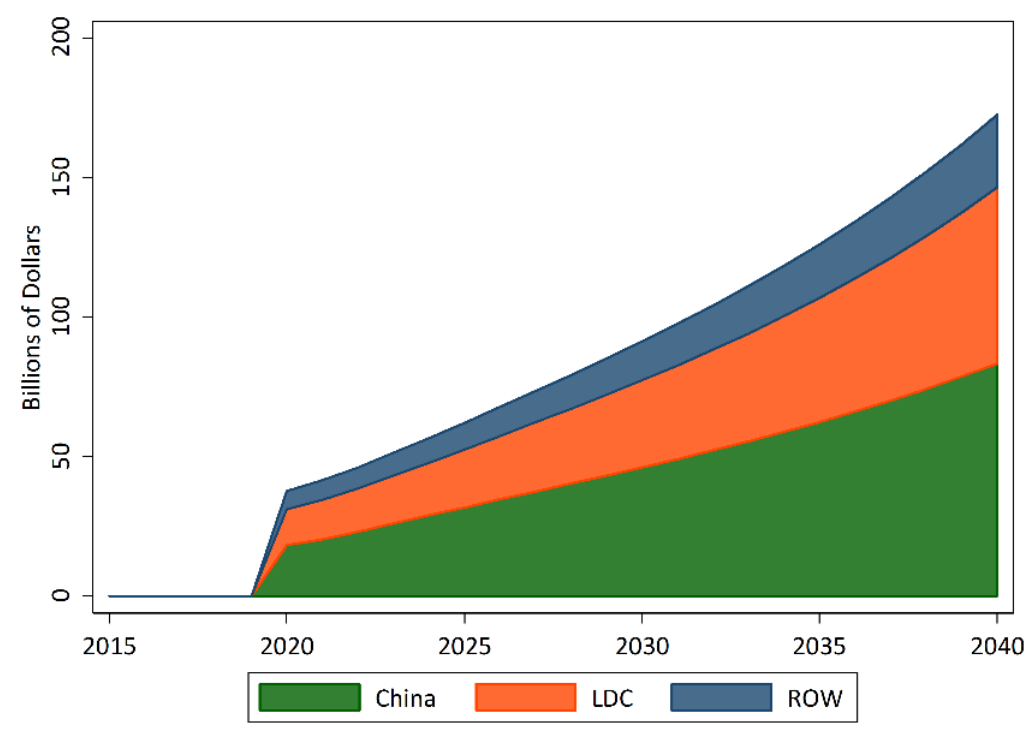

Figure 8. Border carbon revenue by region of origin.

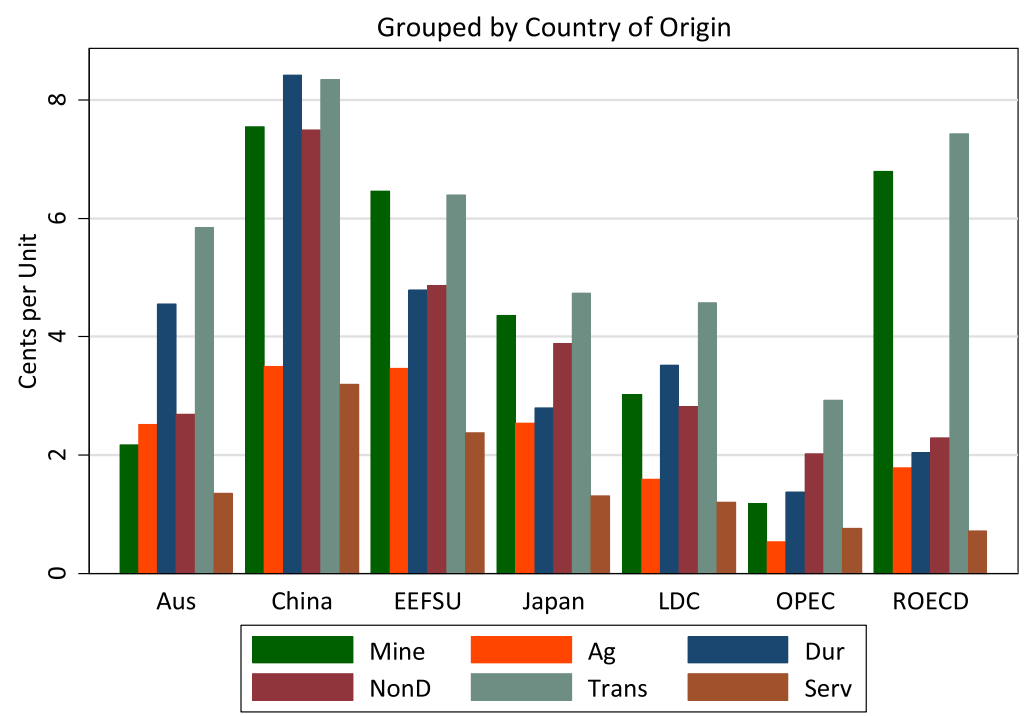

Figure 9. BCAs in 2035.

roughly two percentage points in 2020 and remains close to that through 2040 . In the KT BCA case, the BCA revenue allows an additional one percentage point drop in the capital income tax rate at the outset of the policy, and by 2040 the capital income tax rate is down to a little less than $1 \%$, a 5.6 percentage point drop from its baseline level. 


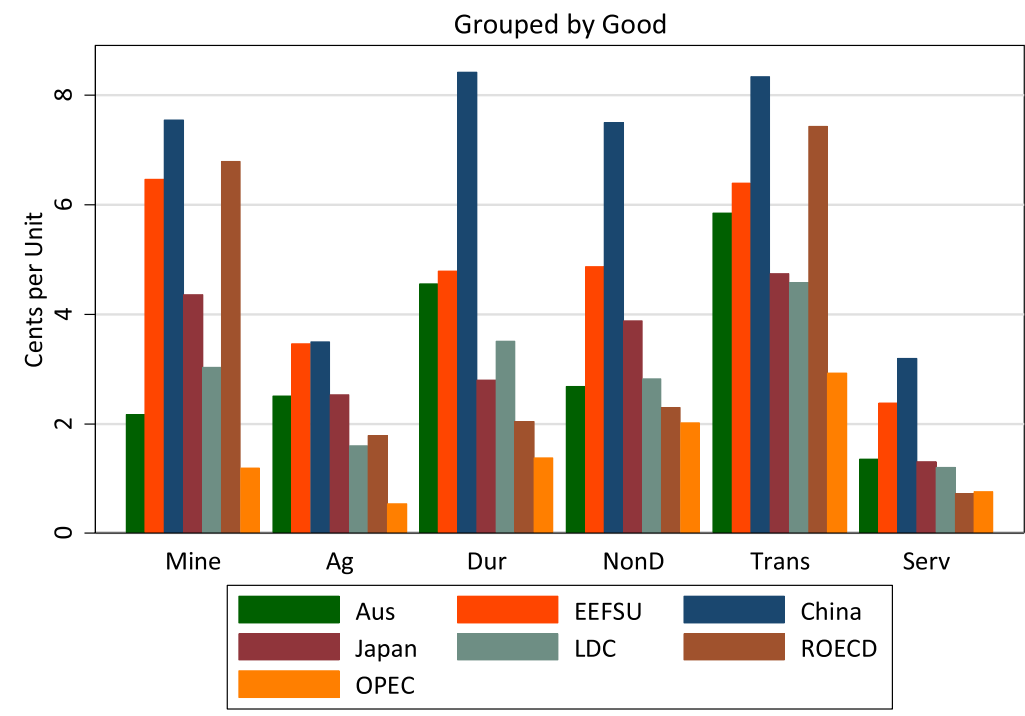

Figure 10. BCAs in 2035.

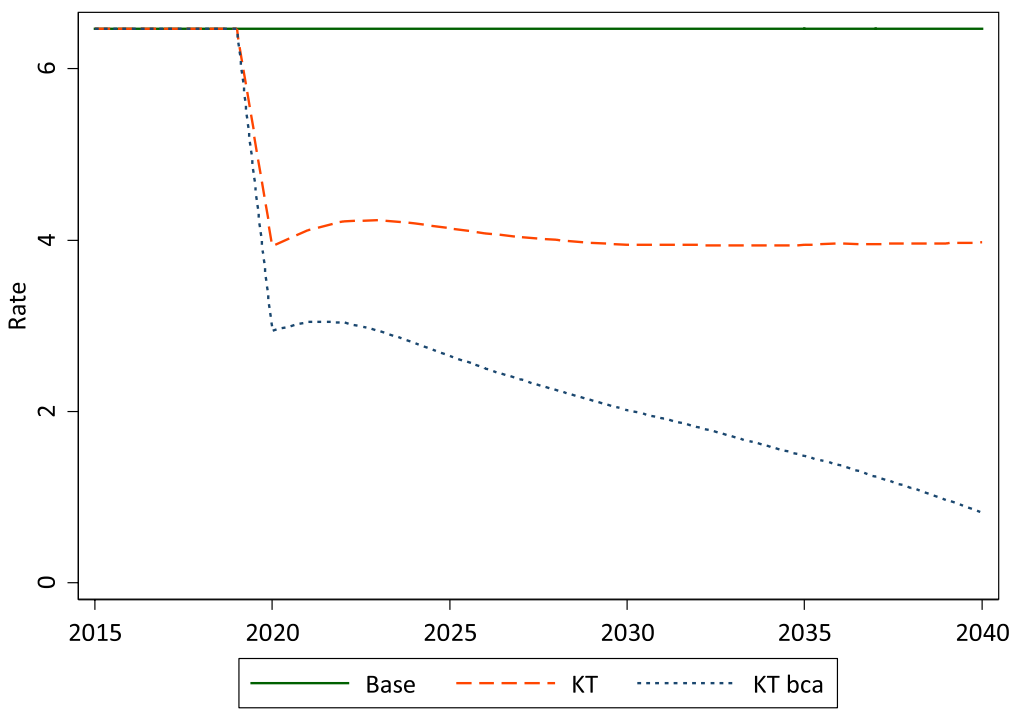

Figure 11. Capital income tax rate.

Figure 12 shows levels of real U.S. GDP for all the scenarios. We see that none of the carbon tax policies cause GDP to fall in absolute terms; rather, they cause a very slight slowing in GDP growth. Indeed, generally the United States achieves the same level of GDP in the policy scenarios only a few months after it does in the no-policy baseline. We emphasize this point here because in other figures below we report changes relative to baseline. While the differences may look dramatic, a careful reading of the vertical axes indicates that many policy effects are less than a percentage 


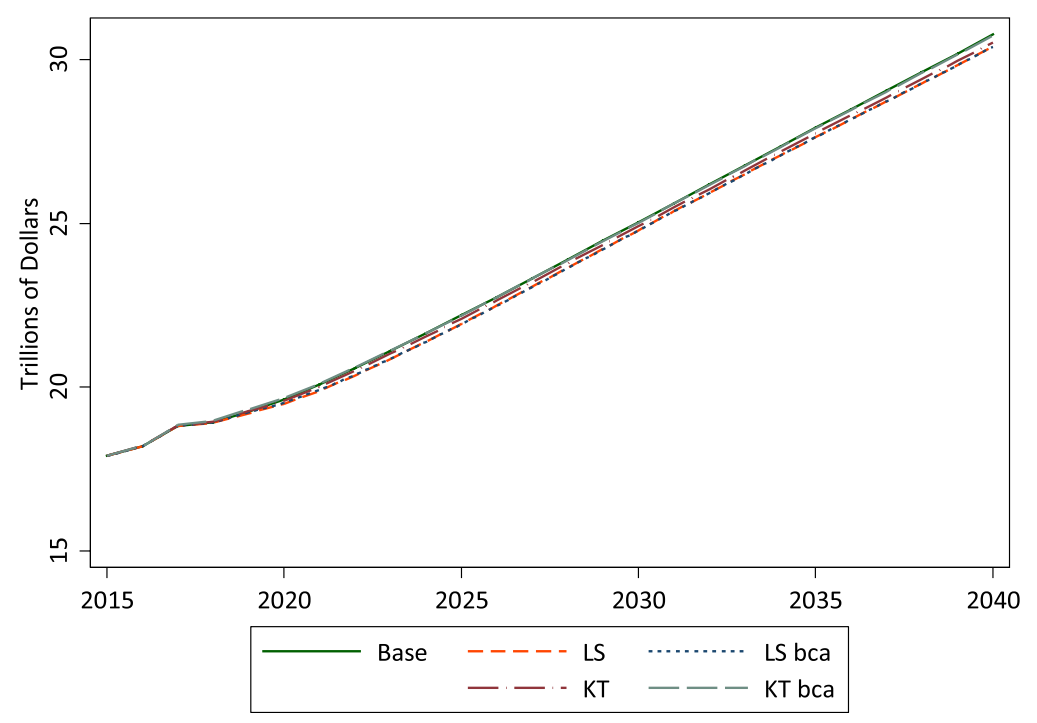

Figure 12. Real U.S. GDP (level).

point or two of those same outcomes in the baseline case. Recall as well that we are not accounting for the potential economic benefits of the climatic damages avoided.

The impact of each policy on U.S. real GDP in percentage terms relative to baseline is shown in Fig. 13. Under both LS and LS BCA, GDP falls slightly during the period preceding imposition of the tax in 2020 while under both KT policies it rises slightly. Once the tax is in place, under the rebate policies, GDP falls by about $1.2 \%$ of its baseline value by 2025 and remains roughly at that level. The BCA makes little difference. Under the capital income tax swaps, the long run impact of the climate policy is less negative, with GDP falling by only about $0.5 \%$ of its baseline by 2030 in the KT scenario and by about $0.1 \%$ in the same year with BCAs. This suggests that from a GDP standpoint, consistent with other modeling studies of carbon taxes in the United States, capital income tax swaps tend to be more pro-growth than lump sum rebates, and here we find that adding the $\mathrm{BCA}$ is even better. But again, we are talking about a difference of around a half of $1 \%$ of GDP, or a few months of GDP growth, after 20 years of the policy.

The next few graphs show changes in the components of GDP relative to baseline GDP. Figure 14 shows the impact of each policy on real consumption. All four policy variants cause an increase in consumption in anticipation of the tax, but the effect is far more pronounced in the LS scenarios. Once the tax is in place, consumption falls back toward its baseline trajectory and then falls below it.

The consumption results for the LS scenarios are driven by a couple of factors. In the LS scenarios, households experience an initial rise in cash income (Fig. 15). This derives in part from a decline in investment (Fig. 16) in those same scenarios during the period before the policy takes effect. Lower investment means lower retained 


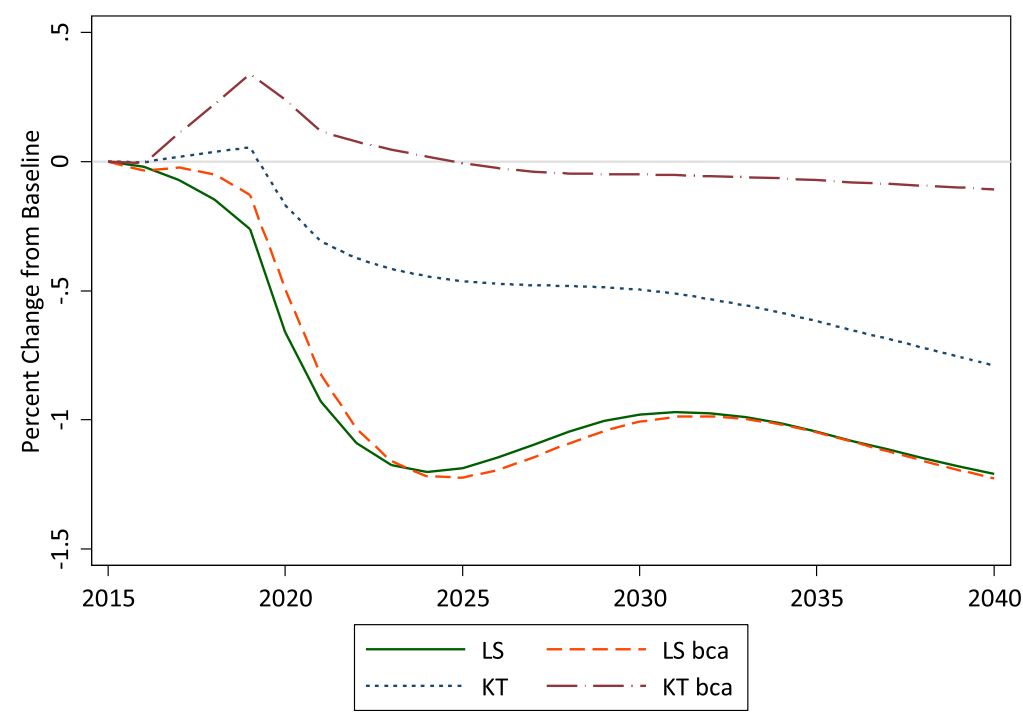

Figure 13. Changes in real U.S. GDP.

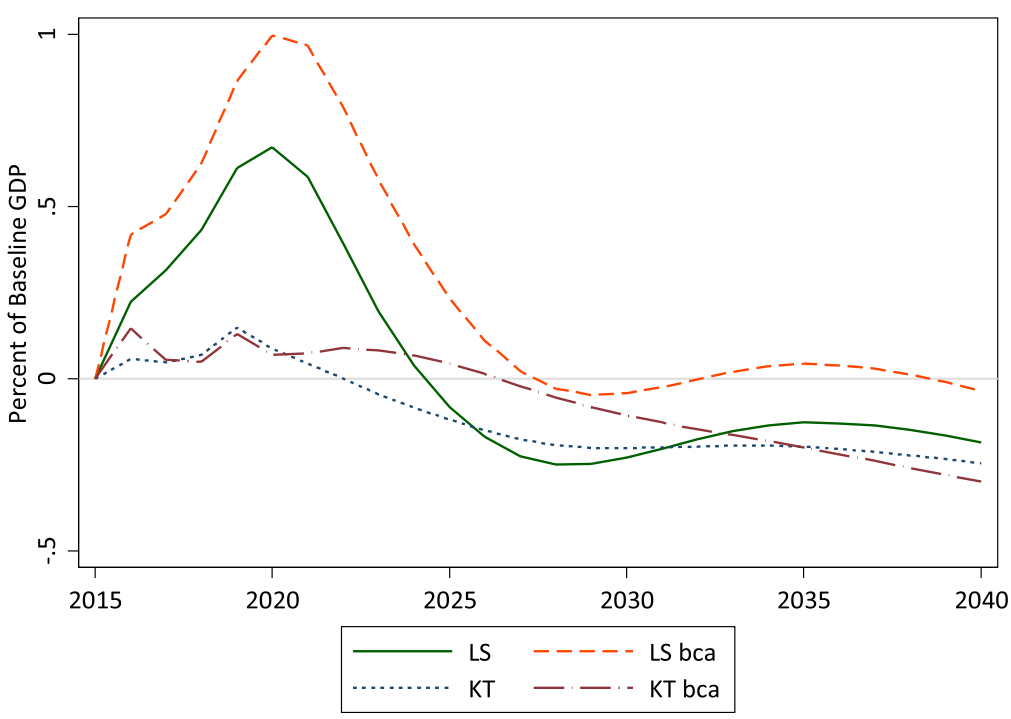

Figure 14. Changes in real U.S. consumption.

earnings on the part of firms. Because investment falls earlier than revenues drop, dividends rise for a time and household cash income increases. Higher income and consumption in the LS and LS BCA scenarios is also due to the increase in income to credit-constrained households from the lump sum transfer of the revenue from the carbon tax. The border tax generates additional revenue, which is also transferred to households in the LS and LS BCA scenarios, reinforcing the early increase in income 


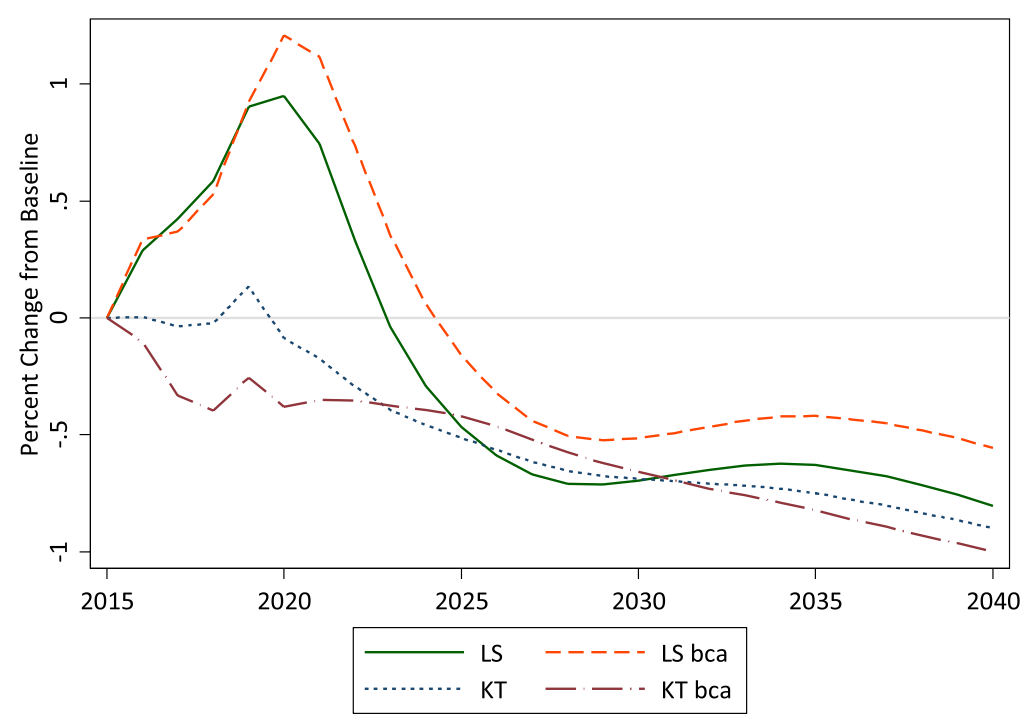

Figure 15. Changes in real U.S. household income.

and consumption. The border adjustments primarily tend to amplify the effects of the lump sum revenue recycling policy.

The impact of the LS and KT policies on investment is sharply different from the results for income and consumption. As shown in Fig. 16, the LS and LS BCA policies cause investment to fall during the anticipation period up to 2020 and then to continue falling immediately after that. By 2030, investment rebounds somewhat but is still about $1 \%$ of GDP below its baseline. Under KT and KT BCA, however, investment

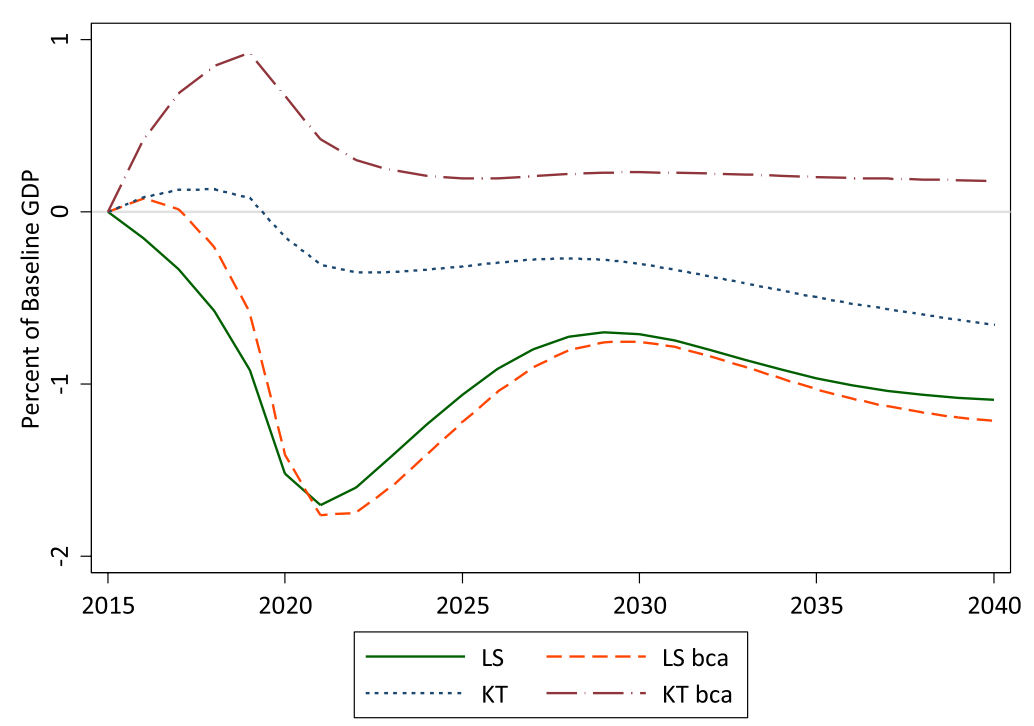

Figure 16. Changes in real U.S. investment. 
rises during the anticipation period and then essentially tends to return to its baseline quickly after the tax is implemented. Investment rises because the revenue in KT and KT BCA funds a reduction in the tax on capital income, and the KT BCA funds a bigger one. This, together with the short term rise in GDP, provides an incentive for firms to increase their capital stocks in the short run, leading to a period of stronger investment. For all but the KT BCA policy, over time, the overall slowdown in economic activity is reflected in a fall in investment relative to baseline. However, the KT policy produces more investment relative to the case where the revenue was given the households.

Figure 17 shows the effects of the policies on net exports. This is decomposed into aggregate exports in Fig. 18 and aggregate imports in Fig. 19. While the carbon tax has only a slight impact on net exports, the decomposition of this into exports and imports is interesting. The carbon tax makes U.S. goods less competitive in world markets because of higher energy costs. This reduces exports (Fig. 18). It also slows the U.S. economy which reduces demand for imports. When an import BCA is imposed in the LS case, imports become more expensive, and the demand for imports falls further. As we will see in Fig. 21, the BCA also leads to an appreciation of the U.S. dollar. This is a conventional result for an increase in tariffs in the international trade literature. A tariff generally causes an appreciation of a country's currency because it makes imports more expensive, lowering the demand for imports and thereby reducing the demand for foreign currency and causing the home currency to appreciate relative to the foreign currency. The appreciation of the U.S. dollar also makes U.S. goods more expensive in world market, so the demand for U.S. exports falls. Thus, although a BCA does not affect the net trade position much (Fig. 17), the

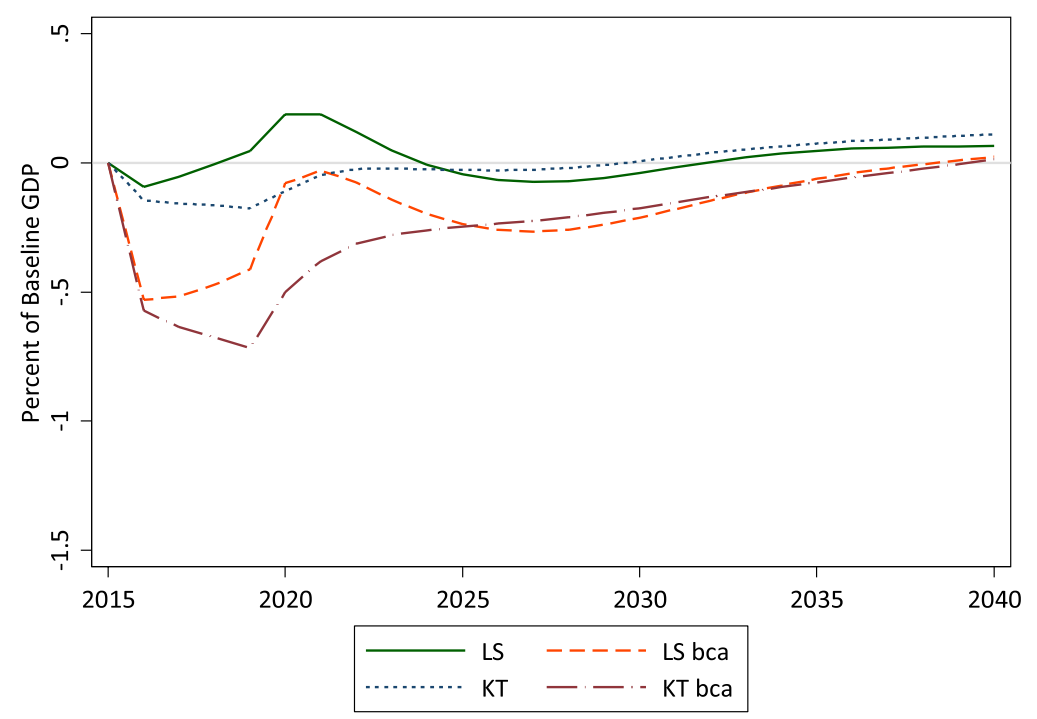

Figure 17. Changes in real U.S. net exports. 


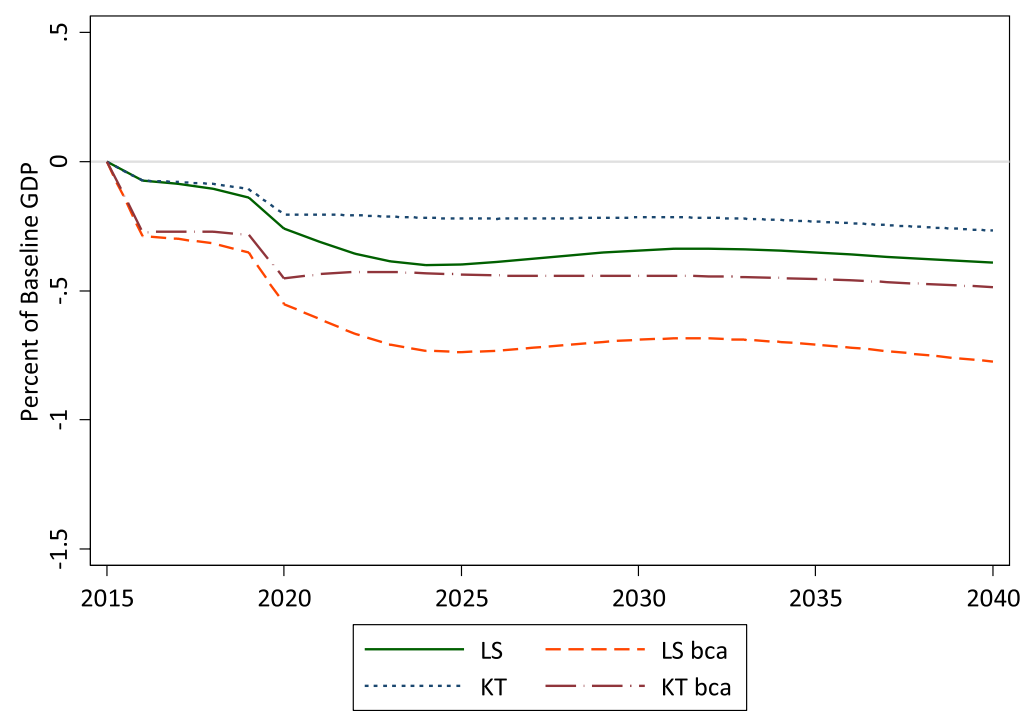

Figure 18. Changes in real U.S. exports.

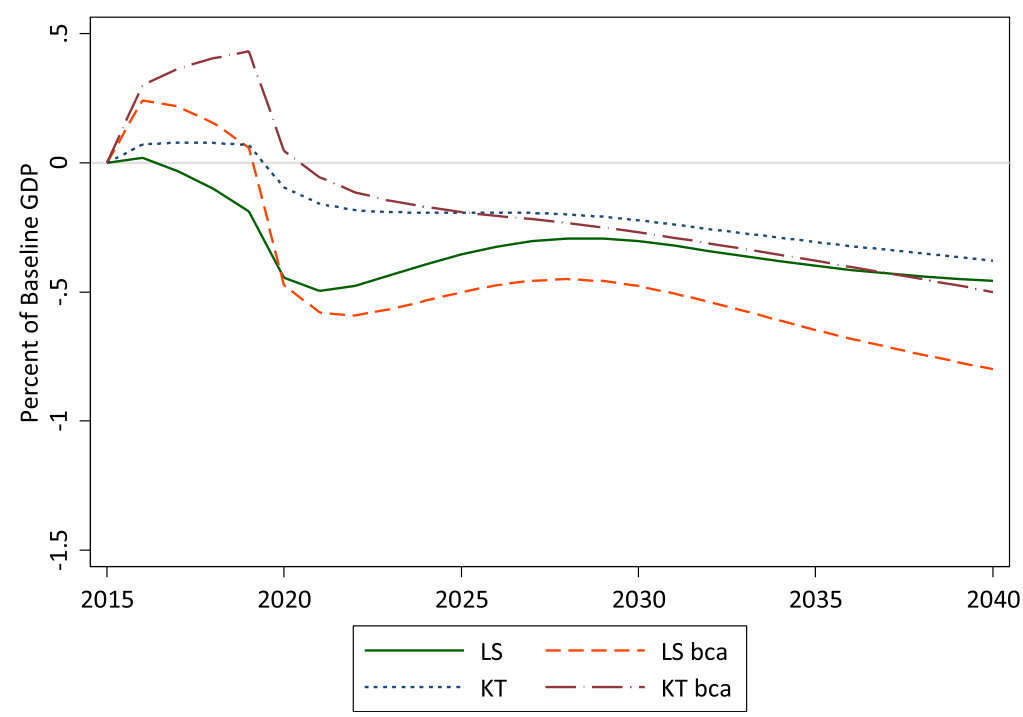

Figure 19. Changes in real U.S. imports.

BCA reduces both imports and exports of U.S. goods. The sectoral composition of this result will be explored further below.

The change in real interest rates (in percentage points) and the percent change in real exchange rates appear in Figs. 20 and 21, respectively. The policies have small effects on U.S. interest rates in the short run and little effect in the long run. All four of the policies tend to appreciate the U.S. real exchange rate modestly right away, in 


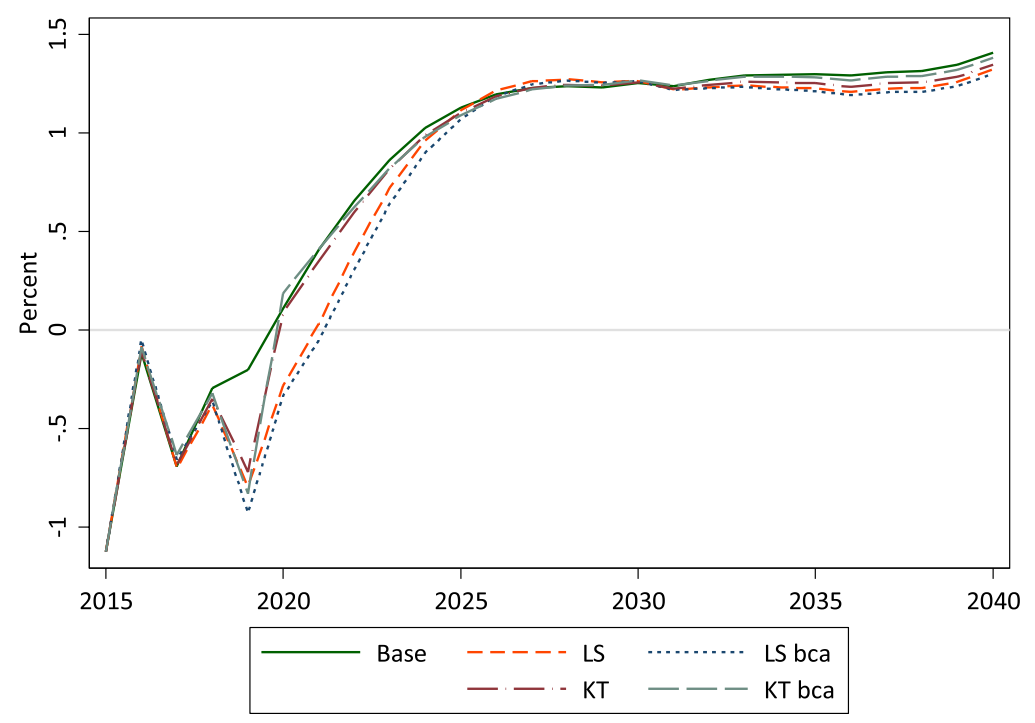

Figure 20. Levels of the real U.S. interest rate in percentage points.

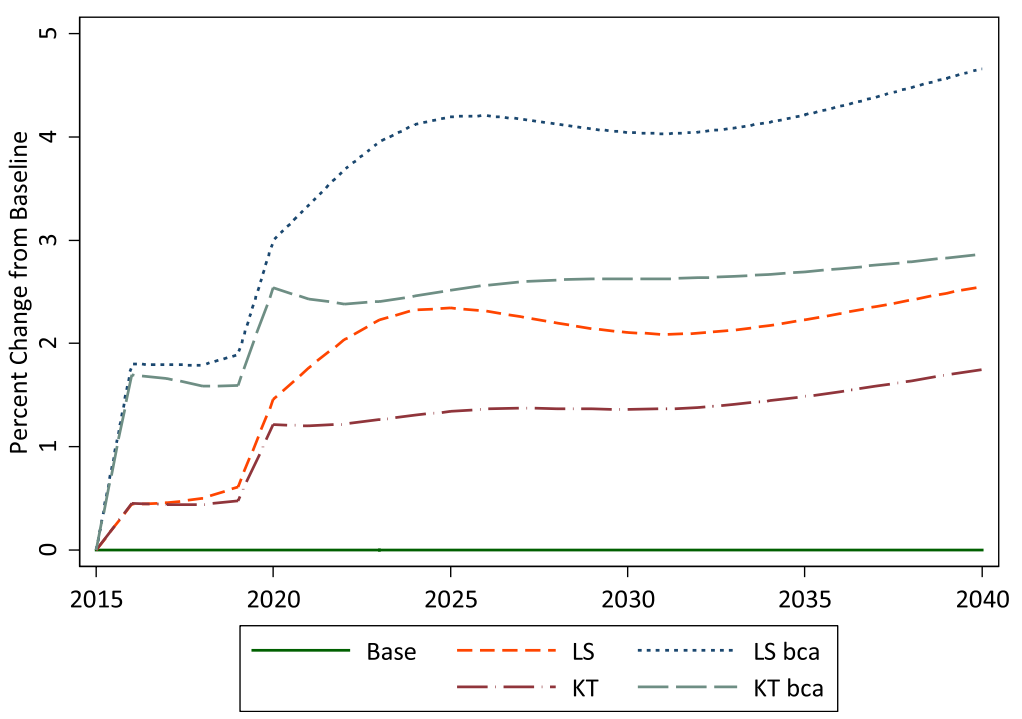

Figure 21. Percent changes in real effective exchange rate of U.S. dollar.

anticipation of the policy, and then appreciate it further in the longer run. The appreciation reflects the assumption in the model that goods from different countries are imperfect substitutes. With a permanent fall in U.S. production, and the assumption that consumers demand goods from all countries, there is a rise in the relative price of U.S. goods in the global economy. To the extent that U.S. goods are more substitutable for goods from other countries, this effect will be smaller. The BCA reduces the 


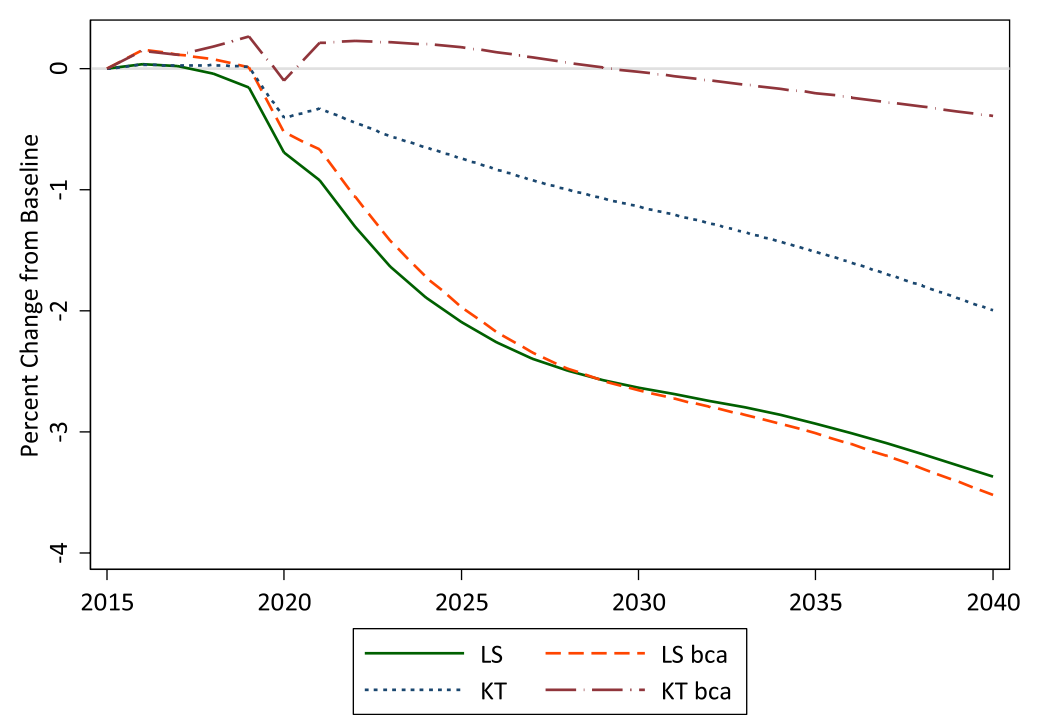

Figure 22. Percent changes in real U.S. wage.

relative price of U.S. goods in world markets which leads to a rise in demand for these goods and therefore in the demand for U.S. dollars to pay for them. Therefore, in equilibrium the U.S. real exchange rate has to appreciate further to clear the market. The LS policy causes a larger appreciation of the real exchange rate than the KT policy because the transfer raises household income, and therefore the demand for U.S. goods, which drives up prices. The KT policy, although also increasing demand for U.S. goods, increases the supply of U.S. goods over time through greater investment. Thus, the price of U.S. goods relative to foreign goods (the real exchange rate) rises by more under the LS policy than the KT policy.

The effect of the two policies on real wages relative to baseline is shown in Fig. 22. Real wages fall relative to the baseline (although the baseline itself is rising) under each carbon tax scenario except KT BCA. The carbon tax reduces the marginal product of capital, which drives down real wages. We find that only in the KS case does the BCA protect the wages of U.S. workers from the effects of a carbon tax.

Figure 23 shows the impact on employment under each policy. Note that in the long run G-Cubed imposes the assumption that the economy eventually returns to full employment. This is achieved through an economy-wide adjustment in the real wage. In the short run, however, real wages are assumed to be slow to adjust and there can be an extended period of employment that is above or below its long term level as a result of a policy change. Figure 23 shows that the two LS policies reduce aggregate employment in the 5-7 years immediately following the introduction of the policy; it takes time for the structural adjustment to occur and for aggregate real wages to adjust enough for employers to soak up workers who have lost their jobs, especially in fossil fuel intensive industries. Adding the BCA to a lump sum rebated carbon tax very 


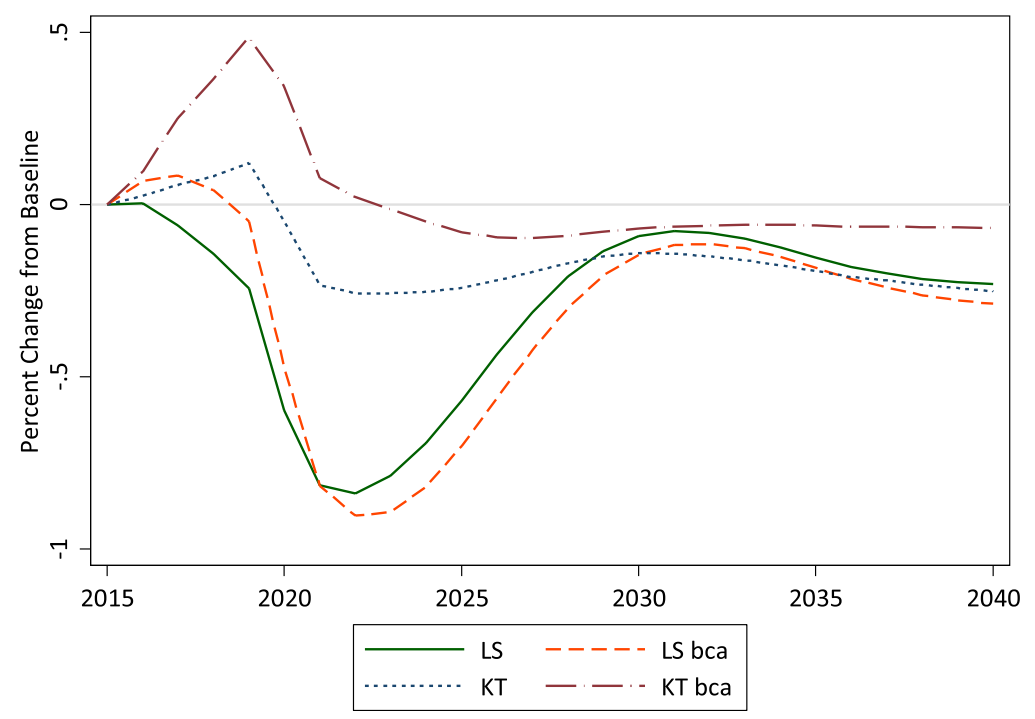

Figure 23. Percent changes in aggregate U.S. employment.

slightly exacerbates the overall loss in employment. In contrast, the employment impact is much smaller under the KT policy and employment actually rises in the short to medium term when the BCA is added.

As Kortum and Weisbach (2017) observe: "Ultimately, the decision to have [border adjustments] and their design has to be based on a belief that they enhance [the home country's] welfare." Figure 24 reports the change in welfare associated with each of the four policy scenarios. We measure the change by computing an intertemporal equivalent variation (EV) for each policy: that is, the change in wealth, at baseline prices, that is equivalent to the policy's impact on the household's intertemporal utility. To put the EVs in context, we report each as a percent of baseline wealth. As would be expected from the results for consumption in Fig. 14, the capital tax policy lowers welfare. Without border adjustments, it is equivalent to a $0.18 \%$ reduction in wealth. Adding a BCA moderates the impact slightly: to $0.17 \%$. The lump sum policy, in contrast, increases welfare. Without border adjustments, it is equivalent to a very slight $0.05 \%$ increase in wealth: the early surge in consumption boosts welfare slightly more than the long term fall lowers it. However, adding the BCAs raises consumption in all years relative to the lump sum policy alone, so the welfare impact is considerably more positive with they are included: the policy produces a gain of $0.32 \%$ of wealth.

These EVs do not account for the benefits produced by the policies in terms of reduced climatic disruption. They also do not account for local environmental and other benefits that result from the decline in fossil fuel combustion. These benefits (such as reduced road congestion) may be more efficiently achieved by other policies, but to the extent they arise from the carbon tax, they are relevant constituents of the 


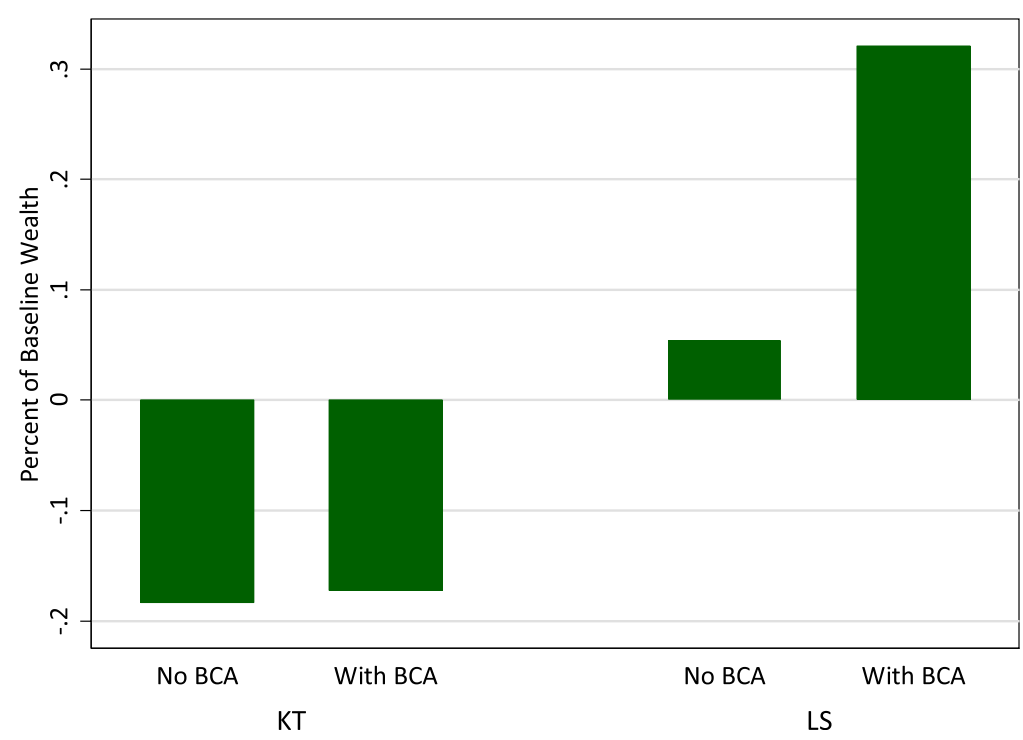

Figure 24. Intertemporal equivalent variations as percentages of baseline wealth.

overall net benefits of the tax. Parry et al. (2015) enumerate the domestic non-climate external costs associated with fossil fuels in the United States. For coal and natural gas, that primarily means mortality risks from air pollution. For gasoline and road diesel, the costs also include extra road congestion, traffic accident risk, and road damage. They estimate that all of these benefits sum to about $\$ 36$ per ton of $\mathrm{CO}_{2}$ abated in the United States. We applied that figure year by year to the reductions in emissions through 2040 to obtain an approximate stream of annual benefits. ${ }^{22}$ We then took the present value of that stream to obtain a benefit measure that can be compared to the EVs reported above. The results are shown in Fig. 25, which reports each of the following in billions of 2015 dollars: the EVs; the present values of the environmental benefits produced; and the net impact of each policy when the EVs and environmental benefits are summed.

\subsection{Results by sector}

We will now turn to the sector-specific results behind the macroeconomic outcomes discussed above. Figure 26 shows the change relative to baseline in 2035 of producer prices for each non-energy sector (as shown in Table 2) under the policies. The graph shows the change in broad prices charged to all buyers of each non-fuel good. Not surprisingly, the extractive and direct energy sectors are hit hardest; the BCA makes little difference.

\footnotetext{
${ }^{22} \mathrm{As}$ noted earlier, this calculation is a first-order approximation that does not account for interactions between changes in environmental conditions and decisions about production and consumption. Moreover, it is driven entirely by nonclimate externalities, so it is a lower bound on the overall benefits from reducing emissions.
} 


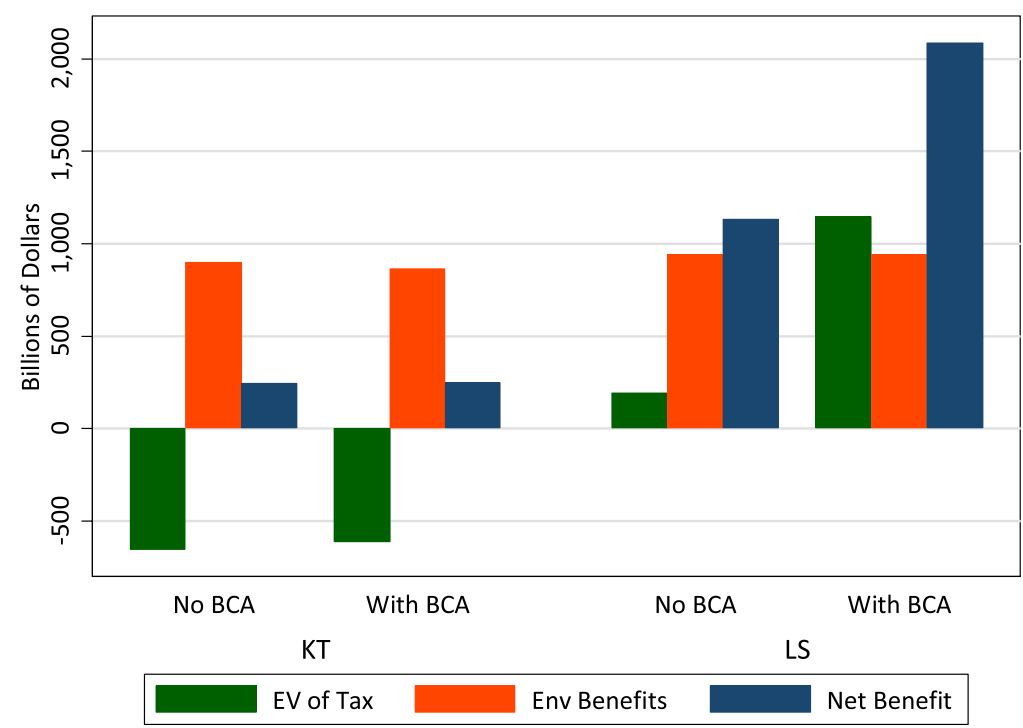

Figure 25. Overall welfare impacts in billions of dollars.

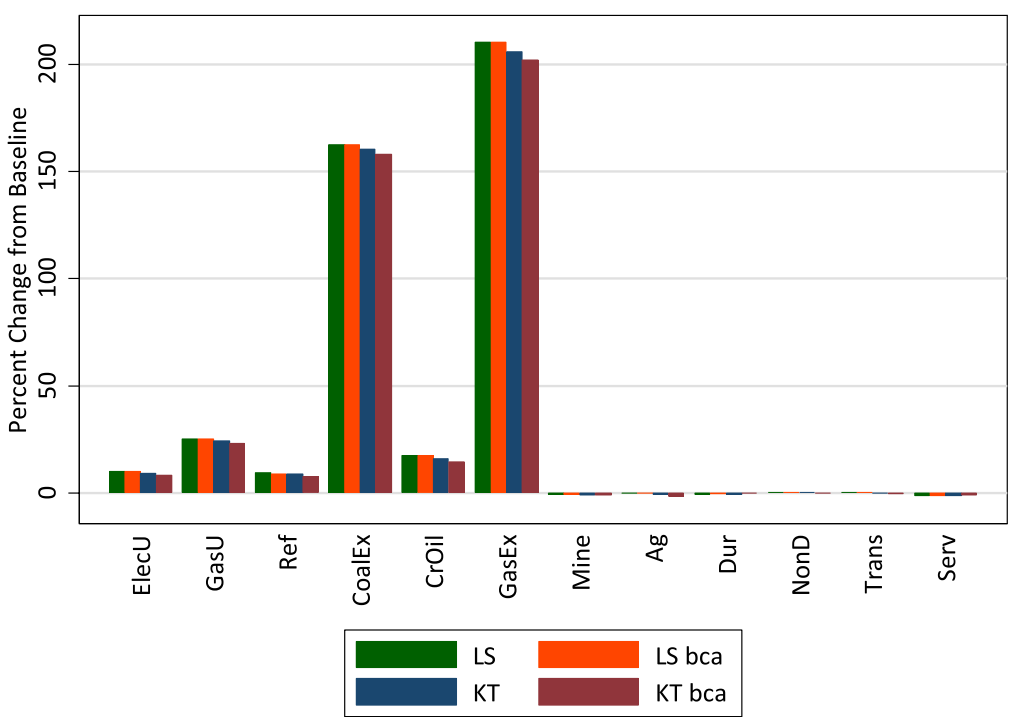

Figure 26. Percent changes in U.S. producer prices in 2035.

Figure 27 shows the impact of the carbon tax policies on output from the 12 core sectors in the model in 2035. Not surprisingly, the largest reductions in output arise in the coal sector, followed by the gas sector and then oil sector. The overall response of energy demands to increases in energy prices is fairly elastic. G-Cubed's key substitution elasticities vary considerably by sector and are listed in Appendix A. The resulting general equilibrium aggregate response ranges from elasticities of about -0.3 for natural gas and -0.5 for coal to closer to -1 for electricity. As a result, the 


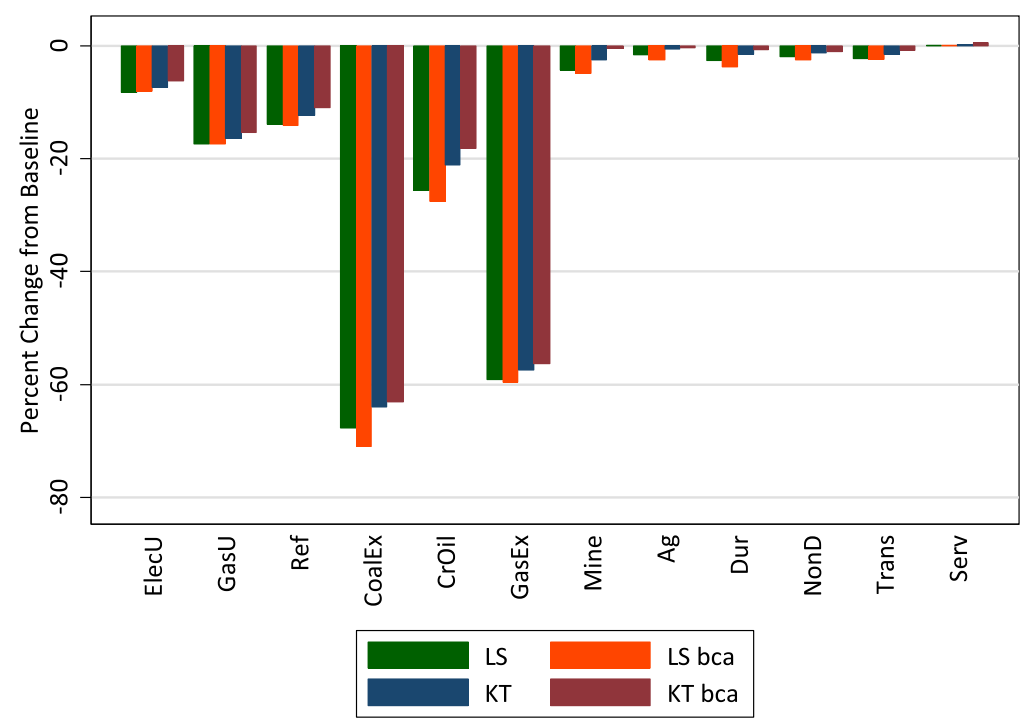

Figure 27. Percent changes in output of each sector in 2035.

model achieves emissions reductions through a relatively large reduction in electricity consumption paired with strong substitution within the electric sector away from coalfired generation.

Because the primary goal of this study is to examine the incremental effects of BCAs, in the next few figures we focus on the results for the non-energy sectors to which they apply. As is clear from the previous two figures, the carbon tax effects are much larger in percentage terms in the energy sectors, so showing all sectors on the same scale would make it hard to see the subtle impact of BCAs on the non-energy sectors. The detailed impacts of carbon taxes on energy sectors are explored in other papers using the G-Cubed model. ${ }^{23}$

To lay the groundwork for understanding the results of the carbon tax and BCAs on trade, we first consider the baseline composition of domestic output, imports, and exports in the United States in 2035, as shown in Fig. 28. The model projects that in 2035 imports and exports will be small relative to domestic output for nearly all sectors, with the important exceptions of durable goods manufacturing and, to a lesser extent, non-durable manufacturing. The figure also shows how significant the services sector is relative to everything else.

Now consider the industry-specific effects in 2035 of the carbon tax on domestic output, imports, and exports for the six non-energy sectors. Figures 29 and 30 show changes in these variables in 2035 relative to baseline. Bars labeled "Dom" show changes in domestic output. Bars labeled "Imp" and "Exp" are changes in imports and exports, respectively. To compare the relative impacts across sectors and scenarios, all of the figures appear on the same vertical scale in percentage point changes from

${ }^{23}$ See McKibbin and Wilcoxen (2013) and McKibbin et al. (2015). 
W. J. McKibbin et al.
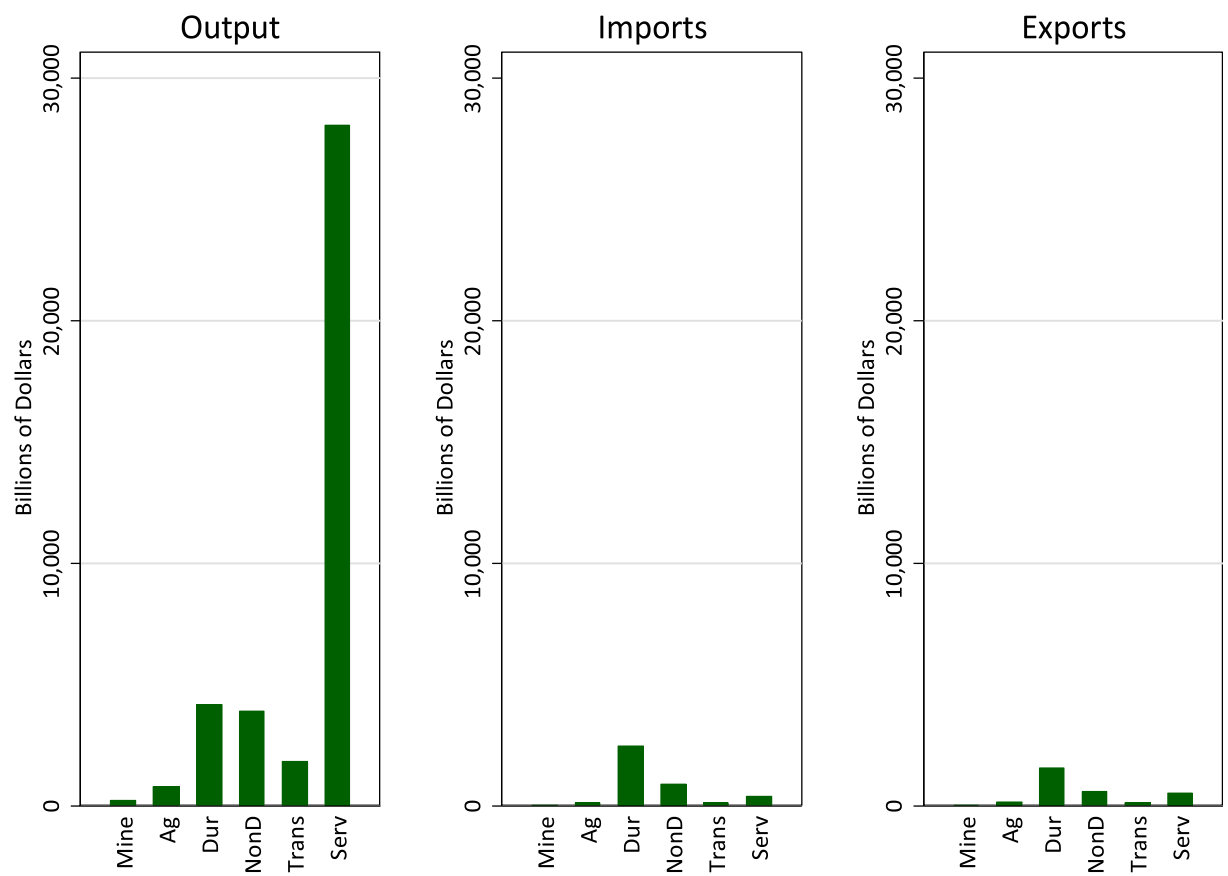

Figure 28. Baseline U.S. output, imports, and exports for non-energy sectors, 2035 (billions of dollars).

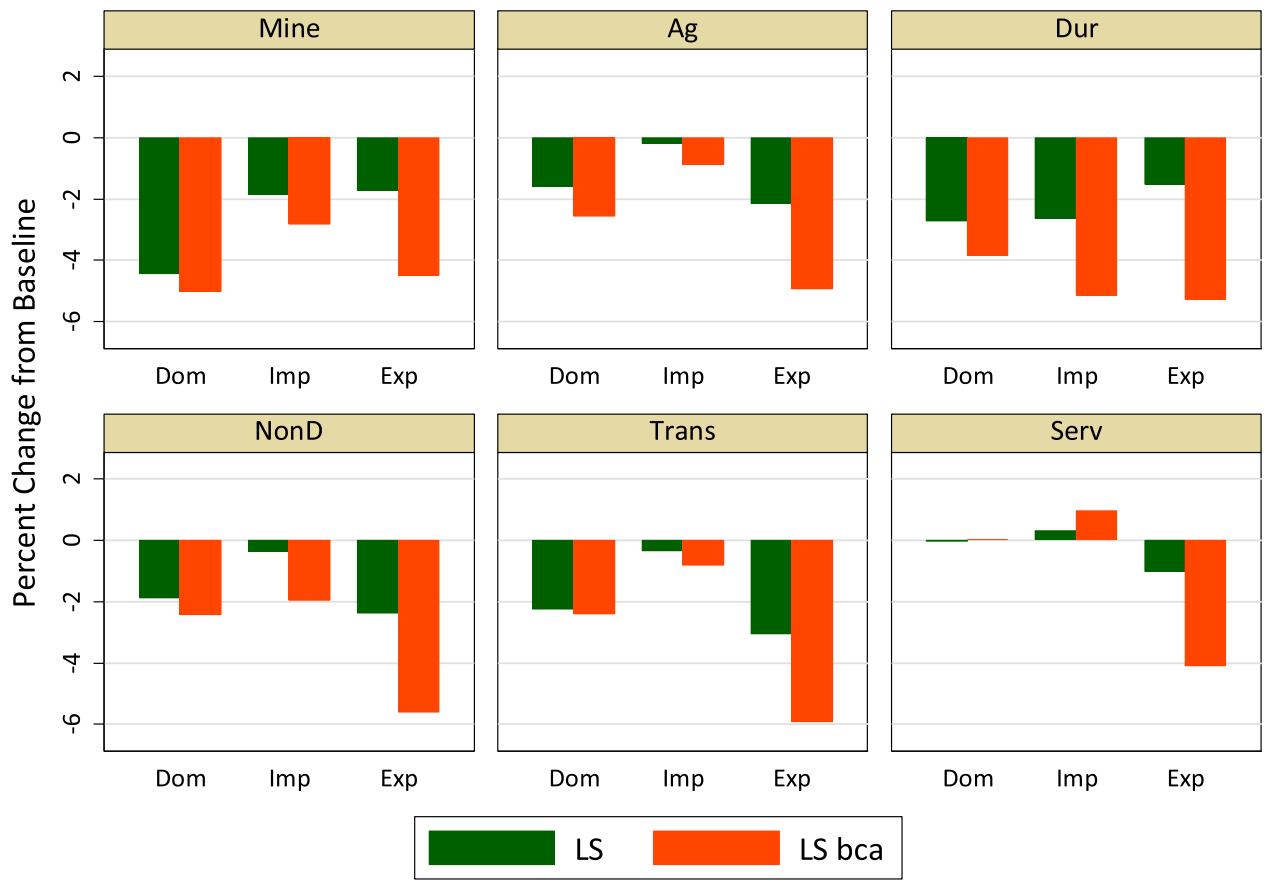

Figure 29. Percent changes in U.S. domestic output, imports, and exports in 2035 by sector: LS scenarios. 


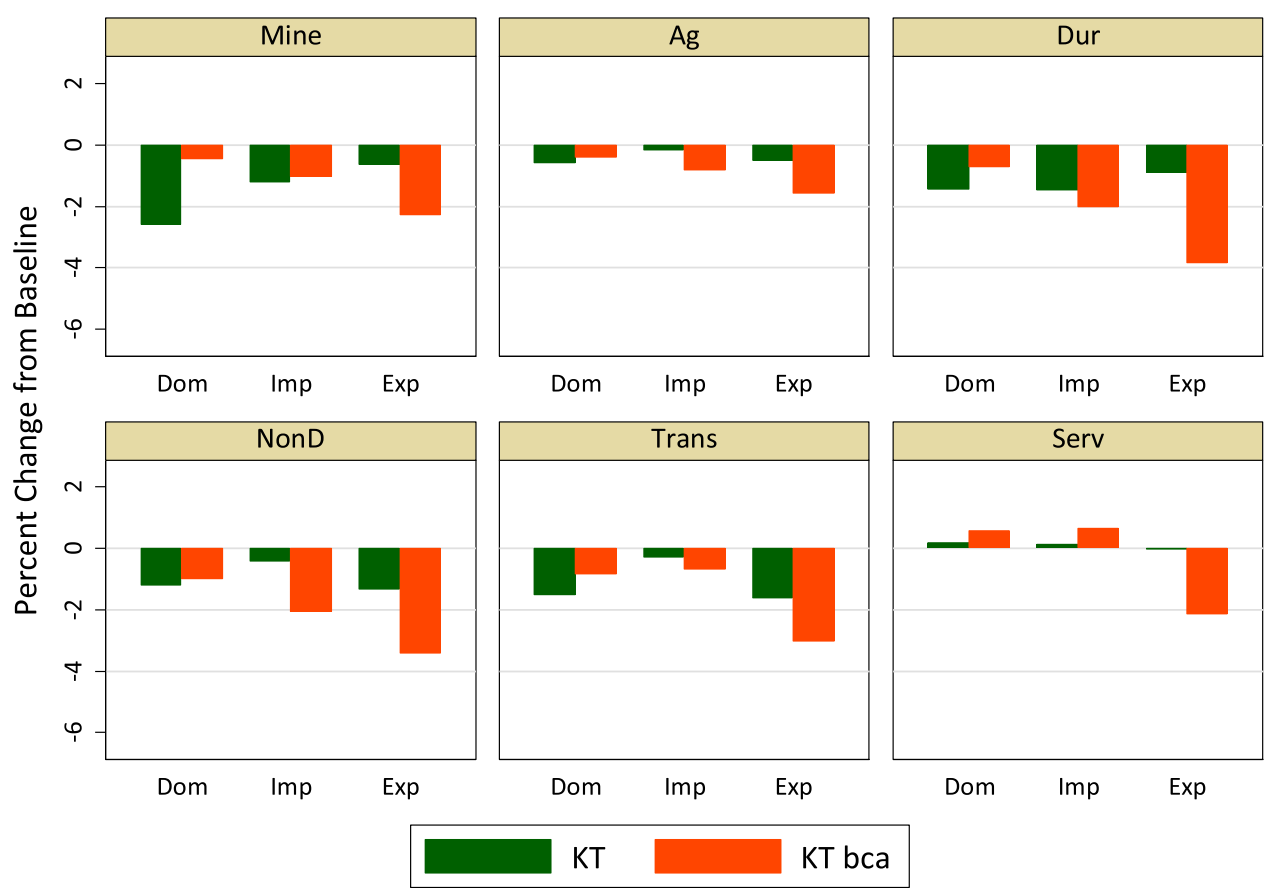

Figure 30. Percent changes in U.S. domestic output, imports, and exports in 2035 by sector: Capital tax scenarios.

baseline. The green bars show the results for the carbon tax policies without BCAs, and the orange bars show the results with the BCAs.

Comparing domestic output across the results in Fig. 29, we see that the carbon tax reduces output in all of the sectors except for services. The two most affected sectors are mining and durable manufacturing, where output declines up to $4 \%$ relative to baseline. In general, output falls significantly more in the LS scenario than the KT scenario. For example, the output decrease is about twice as large or more in the LS scenarios than the KT scenario for mining and agriculture. Stronger results (smaller reductions in output) under KT are consistent with the efficiency gains from the capital income tax swap.

We also see in Figs. 29 and 30 that the BCAs have strikingly different effects in the LS and KT contexts. The BCAs in the LS scenario result in slightly lower domestic output than the LS scenario without the BCAs, thus doing more harm than good. In contrast, BCAs tend to result in higher output in the KT scenarios. For example, the decline in output for durables falls from about $1.5 \%$ to less than half that by imposing BCAs. This results in part from the role of the additional revenue from the BCAs in further reducing the tax rate on capital income, as shown in Fig. 11.

Recall that Fig. 19 showed no evidence of an economy-wide surge in imports upon the imposition of the carbon tax. Figure 29 shows that the same is true in all of individual sectors. Thus, at the level of the broad categories of economic activity in the 
model, we see no evidence of a broad competitiveness problem. Of course, trade in individual subsectors (that is, in narrower segments of the economy than the sectors in the model) may be far more sensitive.

We saw in Fig. 17 that overall net exports across the U.S. economy are lower than baseline in the carbon tax scenarios. Consistent with that, we see in Fig. 29 that in most sectors in percentage terms exports fall by more than imports, particularly in the scenarios with the BCAs and particularly for the LS scenarios. Thus, if policymakers are concerned about net exports from the United States, it may be preferable to impose a carbon tax with no border adjustments than a carbon tax with BCAs only on imports.

Next consider the politically-important durable goods manufacturing sector in more detail. In the LS and KT scenarios, the carbon tax lowers domestic production by roughly the same proportion as it lowers imports. That means that to the extent that the carbon tax reduces the market for durables, it does not disproportionately disadvantage domestic durables relative to imported durables. In both the LS and KT scenarios without BCAs, imports fall a little more than exports, but both fall more in the LS scenario. With BCAs, the capital income tax swap scenario reduces exports far more than imports, whereas with lump sum rebates the two percentage changes are about the same.

These outcomes are an amalgam of several competing factors, in addition to the shift in the relative costs of production in the United States and abroad that results from the carbon tax. First, as we saw in Fig. 21, in general equilibrium the carbon tax induces a stronger U.S. dollar. That has a tendency to increase imports and lower exports. At the same time, in the LS scenarios the carbon tax drives overall economic activity in the United States, particularly investment (Fig. 16), slightly below baseline, and that would tend to lower both imports and domestic output, all else equal. Finally, the carbon tax shifts the composition of goods and services produced and consumed in the U.S. economy, and that can affect domestic output and imports and exports. For example, the carbon tax shifts consumption towards relatively low-emissions-intensive services, which are disproportionately domestically produced. Overall, our results show that if policymakers want to minimize the impact on domestic output, it is more important to focus on choosing an efficient use of the revenue than on addressing trade competition.

Figure 31 shows how the domestic output effects in Fig. 29 translate into employment in the United States in the six non-energy sectors. Each bar is the change in employment in 2035 as a share of total baseline employment in that year. Thus, bars with the same height have to represent the same number of workers, even though the sector sizes vary significantly. We see that overall, the U.S. labor market effects of all of the policies are modest, with no sector losing more than about one quarter of one percentage point of total baseline employment in 2035. The carbon tax produces the largest employment losses in the durable manufacturing sector, and that is the sector in which the BCAs do the most harm in the LS scenarios, resulting in about quadruple the 


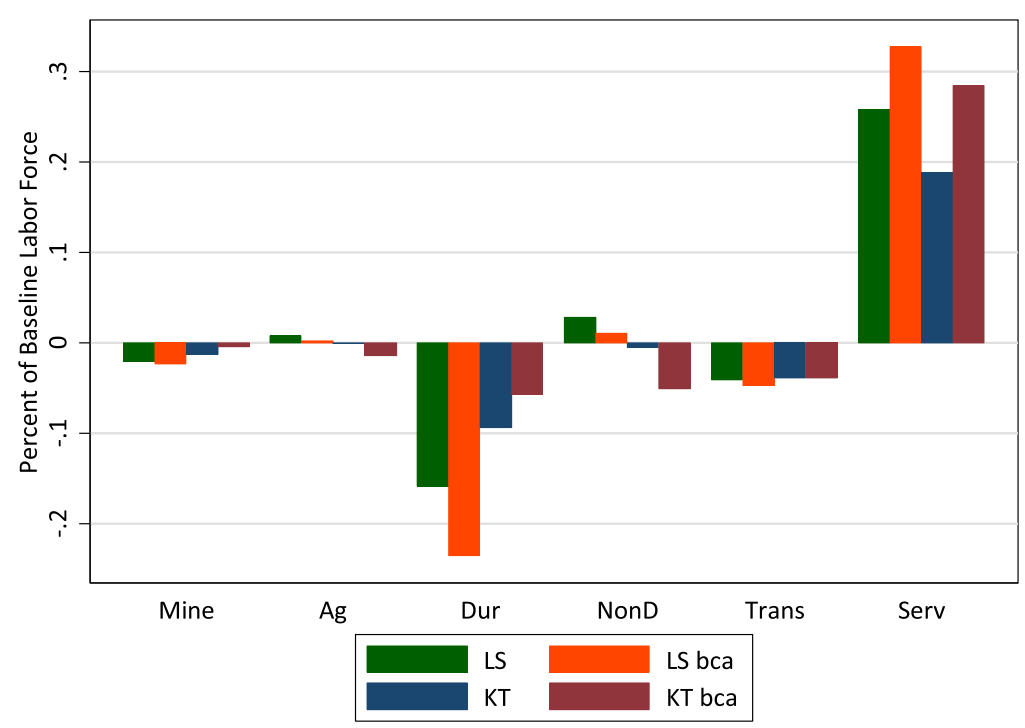

Figure 31. Change in U.S. employment by sector in 2035 (percent of baseline labor force).

employment loss relative to the capital income tax swap. The BCAs improve labor market outcomes in the service sector, however.

\subsection{Results by region}

Because the carbon intensity of products from different countries varies considerably, the BCAs cause different changes in imports across sources. Figure 32 shows percentage changes relative to baseline in U.S. imports and exports of durables and nondurables in 2035 for each U.S. trading partner and for the pair of LS policies; Fig. 33 shows analogous results for the capital tax scenarios. As expected, BCAs cause greater reductions in imports from countries with larger BCAs. For durables, the impacts are largest for Australia, China and EEFSU, while for non-durables they are largest for China, EEFSU and Japan. Because Europe is not subject to a BCA, U.S. imports from Europe are stronger under the BCA policy for both goods. Thus, there is some redirection of imports from other countries of origin to Europe. Also as expected, since the exchange rate is a key mechanism, exports to all trade partners fall more when BCAs are imposed.

Several factors are at work in the durables sector. The BCAs reduce global investment through transmission of the macroeconomic impact of the tax to non-U.S. economies. The BCAs reduce employment most in the trade-exposed sectors. Because durable goods are a large part of the goods purchased for investment, the global reduction in investment directly impacts this sector in all countries.

As shown in Fig. 34, U.S. policies cause changes in the real GDP of other regions. By 2035 real GDP falls slightly for most regions. Because there are no BCAs on imports from the E.U., GDP in the E.U. is very slightly higher reflecting a switch in 


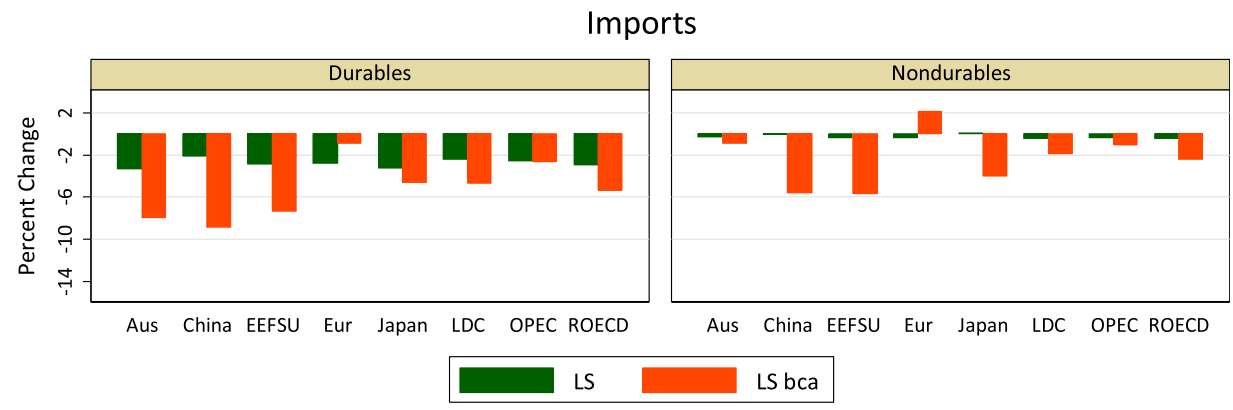

Exports

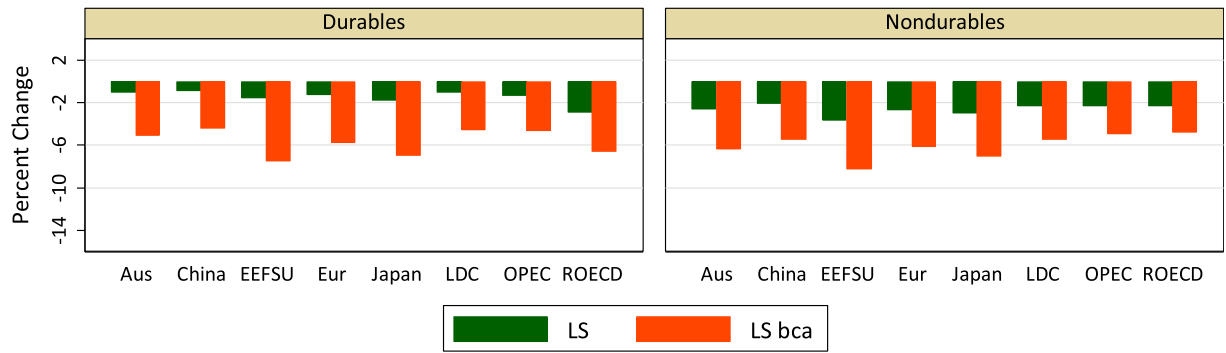

Figure 32. U.S. imports and exports of durables and non-durables in 2035 by country of origin and destination: LS scenarios (percentage changes relative to baseline).

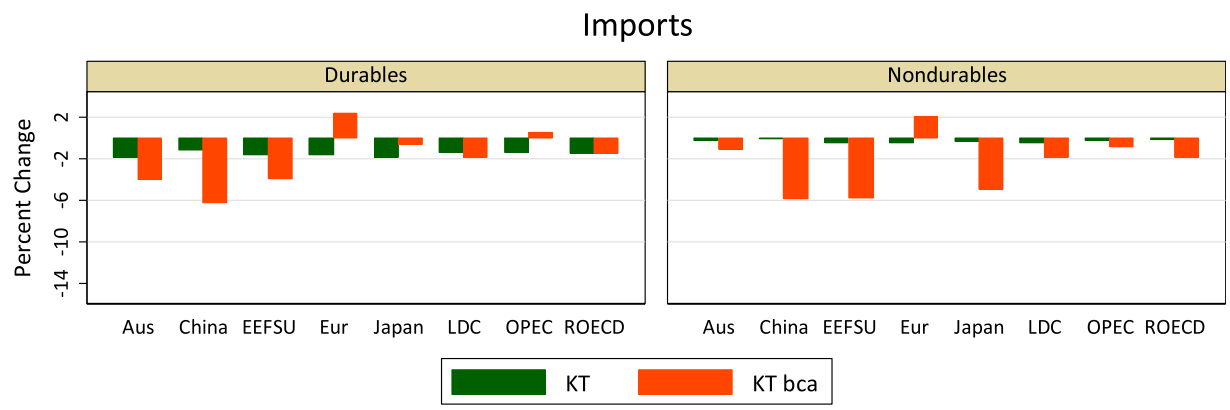

Exports

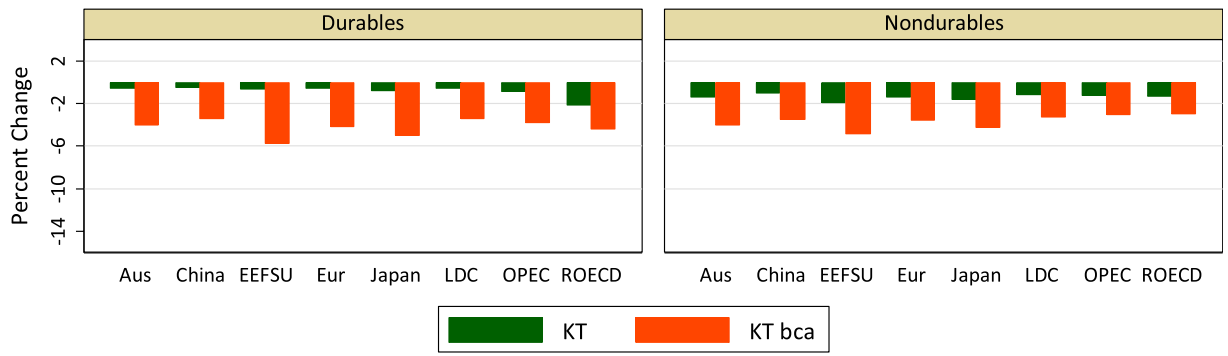

Figure 33. U.S. imports and exports of durables and non-durables in 2035 by country of origin and destination: KT scenarios (percentage changes relative to baseline). 


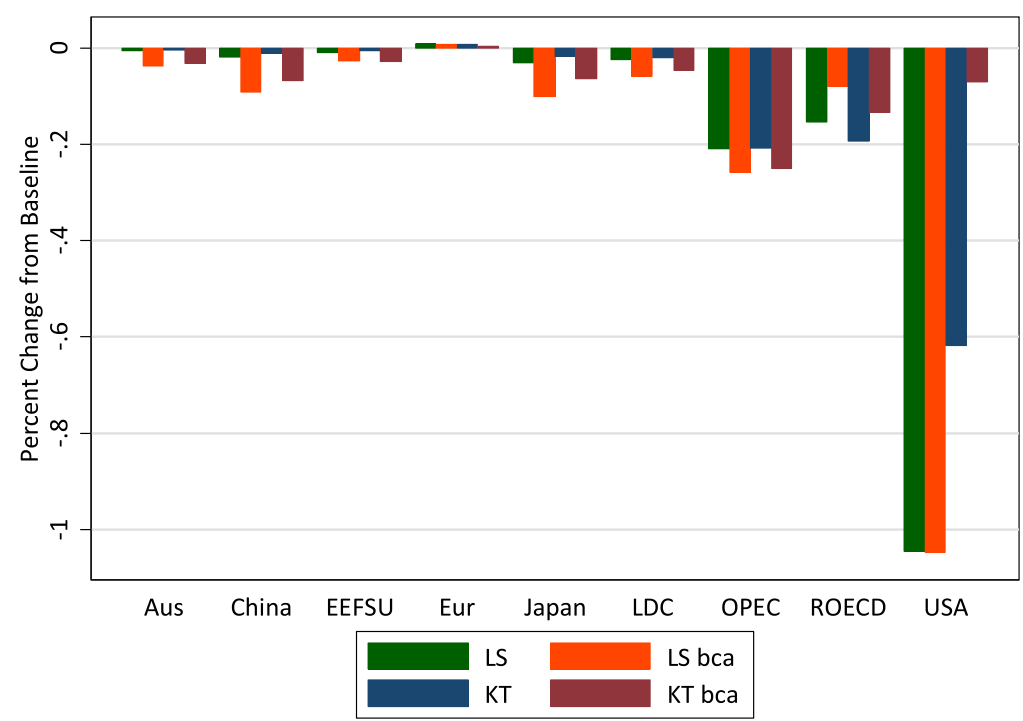

Figure 34. Impacts on real GDP by region in 2035 .

world demand towards Europe as a result of the U.S. border carbon policy. The negative spillovers of the carbon policies are largest for OPEC and ROECD (which in G-Cubed is mostly Canada). The BCAs accentuate the spillovers for all regions except for ROECD.

Finally, as seen in Fig. 35, positive and negative leakages arise in different regions from the carbon tax and BCAs, but in all cases they are very small relative to the

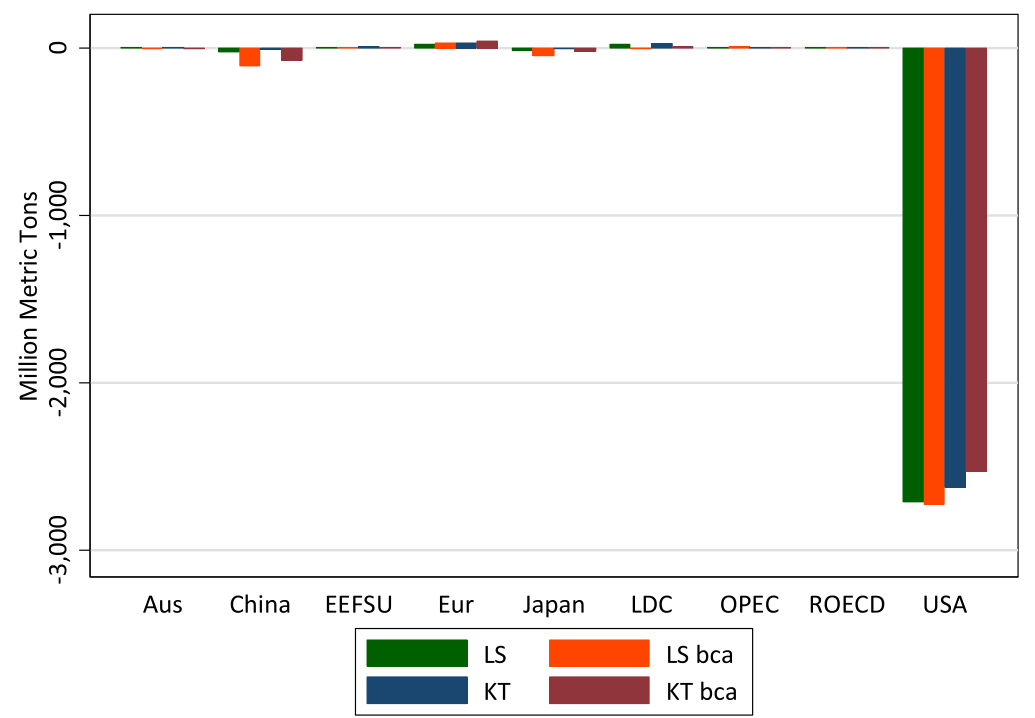

Figure 35. $\mathrm{CO}_{2}$ emissions by region in 2035 . 
emissions decline in the United States. Emissions in China fall on net as a result of the U.S. carbon tax policy because lower U.S. economic growth slows GDP in China and reduces the demand for energy more than emissions rise from a competitiveness advantage from the U.S. carbon price. BCAs induce a larger negative impact on Chinese emissions but also very slightly greater leakage to Europe because Europe is not subject to the BCA.

\section{Conclusion}

In this study, we examine an illustrative carbon tax imposed only in the United States. The tax applies economy-wide to all sources of $\mathrm{CO}_{2}$ emissions from fossil energy use. We impose the tax beginning in 2020, starting at $\$ 27$ per ton of $\mathrm{CO}_{2}$, and we increase the tax rate annually by $5 \%$ over inflation until 2050 . In years after 2050 , we hold the carbon tax rate constant at its 2050 level.

We model two different assumptions about how the carbon tax revenue is used. One assumes the revenue is returned to households each year as a lump sum rebate, and the other assumes the revenue is used to reduce the marginal tax rate on capital income.

We also run a variation on each policy in which import BCAs are imposed to account for the total embodied carbon in each non-fuel import from each country of origin other than Europe. The revenue from the BCAs is returned to households or firms according to the same assumptions as the core policies. We treat European goods as exempt from border adjustments on the grounds Europe has adopted policies that are very roughly comparable to the tax being imposed in the United States.

Consistent with earlier studies, we find that the carbon tax raises considerable revenue and reduces $\mathrm{CO}_{2}$ emissions significantly relative to baseline, no matter how the revenue is used. Gross annual revenue from the carbon tax with lump sum rebating and no BCA begins at $\$ 110$ billion in 2020 and rises gradually to $\$ 170$ billion in 2040 . By 2040, annual $\mathrm{CO}_{2}$ emissions fall from 5.5 billion metric tons (BMT) under the baseline to 2.4 BMT, a decline of 3.1 BMT, or 57\%. Cumulative emissions over 2020 to 2040 fall by 48 BMT.

Also consistent with earlier studies, we find that the carbon tax has very small overall impacts on GDP, wages, employment, and consumption. A long literature discusses the merits of a carbon tax relative to regulatory measures and the relative merits of different ways to use the revenue of a carbon tax. A tax reform that uses a carbon tax to reduce or replace other distortionary taxes in the fiscal system can improve economic efficiency. Some evidence suggests that the costs of market-based policies without the revenue-recycling benefit may actually exceed those of traditional regulatory approaches like emissions standards, at least in the short run. ${ }^{24}$ Our results are consistent with the literature in that we find that different uses of the revenue from the carbon tax result in slightly different levels and compositions of GDP across

${ }^{24}$ Parry and Williams (2012). 
consumption, investment, and net exports. Overall, using carbon tax revenue to reduce the capital income tax rate results in better macroeconomic outcomes than using the revenue for lump sum transfers. Indeed, even while achieving remarkable emissions reductions, the policy results in the U.S. economy reaching the output projections in 2040 only about three months later than it would without the carbon tax.

The G-Cubed model is uniquely suited to investigating the effects of these policy scenarios on emissions leakage, trade, and investment flows. We find no evidence of significant leakage. If anything, the slight slowing of the U.S. economy and demand for imports result in lower emissions abroad. We find that the carbon tax increases the input price of energy, which lowers U.S. exports and slows the U.S. economy, which in turn reduces demand for imports. When an import BCA is imposed, imports become more expensive, and the demand for imports falls further. The BCA also leads to a conventional result from the international trade literature for an increase in tariffs: the U.S. dollar strengthens. A tariff generally causes an appreciation of a country's currency: as the demand for imports falls, the demand for foreign currency falls, which strengthens the home currency relative to the foreign currency. The appreciation of the U.S. dollar also makes U.S. goods more expensive in world market so the demand for U.S. exports falls. Thus, although a BCA does not affect the U.S. net trade position much, it reduces both imports and exports of U.S. goods.

While the intent of BCAs is to protect U.S. workers from the effects of a carbon tax, we find they can actually have the opposite result, depending on how the revenues are used. To our knowledge, this is the first study to identify the potential linkages between the effect of a BCA and the use of carbon tax revenue. In the lump sum rebate scenarios, the BCAs reduce employment most in the trade-exposed sectors. The largest effect is on durable manufacturing. This is partly a price effect from the stronger U.S. dollar, but it is also because the BCAs reduce global investment through transmission of the macroeconomic impact of the carbon tax to non-U.S. economies. Because durable goods are a large part of the goods purchased for investment, the global reduction in investment directly impacts this sector in all countries. In the capital tax swap scenarios, the BCAs generally improve U.S. employment outcomes, including in trade-exposed sectors.

Future work could extend the analysis to include a BCA on exports. Such a policy would provide rebates to U.S. exporters of the carbon taxes paid during production of their goods. The overall impact of an export BCA would depend on the interaction of similar factors to those discussed above for the import BCA. There would be a price effect as the export BCA lowers the price of energy-intensive exports, which would tend to raise demand, and hence production, of those goods. However, the export BCA would also lower the amount of revenue available for an lump sum rebate or a reduction in the capital tax rate, hence reducing output through macroeconomic reductions in demand. Finally, making U.S. exports more attractive would tend to strengthen the U.S. dollar, partially offsetting the price effect for energy-intensive exports and reducing demand for non-energy-intensive exports. 
Future work could also investigate arguably more realistic scenarios in which: (1) countries retaliate against a U.S. BCA, or (2) the United States does not price carbon and other countries impose border adjustments against carbon-intensive U.S. goods (updating McKibbin and Wilcoxen (2009), for example). Likewise, a BCA may differ substantially from the version we model here, so the question arises how other approaches, such as narrowing the set of goods or basing the BCA on domestic carbon intensity, would affect the results. The latter change, using BCAs based on domestic carbon intensity, would have a significant impact because it would substantially reduce the revenue generated by the BCAs. In particular, current production in the U.S. is considerably less carbon intensive than production in China, so switching the basis for the BCAs would reduce near-term revenue. More importantly, however, our baseline assumptions imply that China's emissions intensity remains significantly higher than that of the U.S. through at least 2040. Although China's emissions intensity improves substantially over that time, the U.S. improves as well and remains ahead of China throughout the period. By reducing the amount of revenue produced by the BCAs, the switch would cause the BCA policies to look more like their nonBCA counterparts.

In sum, a carefully designed carbon tax in the United States can reduce emissions significantly with minimal effect on the economy. We find no evidence of meaningful emissions leakage abroad, even when the U.S. policy is unilateral. Using carbon tax and BCA revenue to reduce distortionary taxes produces better economic outcomes overall and for most individual sectors. To the extent that policymakers wish to protect the interests of EITE industries with BCAs on imports, they should endeavor to tailor the adjustments to narrow, particularly vulnerable, subsectors so as not to inadvertently appreciate the U.S. dollar and do more harm than good overall.

\section{Acknowledgments}

The Brookings Institution is a private non-profit organization. Its mission is to conduct high quality, independent research and, based on that research, to provide innovative, practical recommendations for policymakers and the public. The conclusions and recommendations of any Brookings publication are solely those of its author(s), and do not reflect the views of the Institution, its management, or its other scholars. Support for this publication was generously provided by the Alex C. Walker Foundation. Authors thank Nicholas Montalbano for his research assistance and three anonymous reviewers for their helpful comments. Brookings recognizes that the value it provides is in its absolute commitment to quality, independence and impact. Activities supported by its donors reflect this commitment and the analysis and recommendations are not determined or influenced by any donation. 


\section{Appendix A. Key Parameters of the Model}

G-Cubed is documented in detail in McKibbin and Wilcoxen (2013). This appendix provides several sets of U.S. parameters from the model that are particularly relevant for this study. Table A.1 shows the substitution elasticities at two key tiers of each production sector's cost function. The output tier combines inputs of capital, labor, energy, and materials. Substitution is particularly elastic in agriculture, and fairly elastic in petroleum refining, crude oil extraction, durable goods, and transportation. The energy tier builds a sector-specific energy input out of purchases of individual energy goods. Elasticities at that level are relatively large for mining, agriculture and durable goods. The elasticity is not relevant for the electricity generation sectors because none of the sectors substitute between energy sources, so it is shown as "NA". Sector 1 is omitted in both tables because it corresponds to electricity delivery and is represented differently in the model.

For households, the analogous parameters are 0.8 for the top tier elasticity of substitution between household purchases of capital, labor, energy, and materials, and 0.5 for substitution between individual energy goods.

Table A.1. Output tier substitution elasticities by sector.

\begin{tabular}{lcll}
\hline Number & Name & Output & Energy \\
\hline 2 & Gas utilities & 0.2 & 0.2 \\
3 & Petroleum refining & 0.543 & 0.2 \\
4 & Coal mining & 0.2 & 0.159 \\
5 & Crude oil extraction & 0.493 & 0.137 \\
6 & Natural gas extraction & 0.2 & 0.137 \\
7 & Other mining & 0.5 & 1.147 \\
8 & Agriculture and forestry & 1.283 & 0.671 \\
9 & Durable goods & 0.410 & 0.804 \\
10 & Non-durables & 1.0 & 1.1 \\
11 & Transportation & 0.537 & 0.5 \\
12 & Services & 0.256 & 0.321 \\
13 & Coal generation & 0.2 & NA \\
14 & Natural gas generation & 0.2 & NA \\
15 & Petroleum generation & 0.2 & NA \\
16 & Nuclear generation & 0.2 & NA \\
17 & Wind generation & 0.2 & NA \\
18 & Solar generation & 0.2 & NA \\
19 & Hydroelectric generation & 0.2 & NA \\
20 & Other generation & 0.2 & NA \\
\hline
\end{tabular}

\section{Appendix B. Calculating the Border Adjustments}

This appendix explains how to calculate and impose a BCA on imports for a given carbon tax. 


\section{Step 1: Construction of carbon intensity coefficients}

Let $A_{R}$ be a matrix of IO coefficients for region $R, X_{R}$ be a vector of industry outputs, and $F_{R}$ be a vector of final demands. Total demand for all goods will be the sum of intermediate and final demands: $A_{R} X_{R}+F_{R}$. When demand and supply are equal in every market, the following will hold:

$$
A_{R} X_{R}+F_{R}=X_{R} .
$$

Solving for the industry output needed to support a given final demand vector $F_{R}$, and defining matrix $\Gamma_{R}$ to be the Leontief inverse along the way, gives the following:

$$
\begin{aligned}
& F_{R}=\left(I-A_{R}\right) X_{R}, \\
& \Gamma_{R}=\left(I-A_{R}\right)^{-1}, \\
& X_{R}=\Gamma_{R} F_{R} .
\end{aligned}
$$

Element $\Gamma_{R i j}$ will be the total requirement of input $i$ needed in region $R$ to make one final-demand unit of good $j$.

The carbon intensity of good $j$ can be computed by multiplying good $j$ 's total fuel inputs by the carbon coefficient associated with each one. If the carbon coefficient for good $i$ in region $R$ is given by $\alpha_{R i}$, the carbon intensity coefficient $c_{R i}$ of one unit of good $j$ will be

$$
c_{R j}=\sum_{i} \alpha_{R i} \Gamma_{R i j}
$$

In many versions of the G-Cubed model, the fossil fuel sectors are 4, 5, and 6. Using a mix of model and algebraic notation, this expression could be written as

$$
c_{R i}=\operatorname{carcoef}_{4 R} \Gamma_{R 4 j}+\operatorname{carcoef}_{5 R} \Gamma_{R 5 j}+\operatorname{carcoef}_{6 R} \Gamma_{R 6 j} .
$$

The units of $c_{R i}$ would be the same as carcoef: million metric tons of carbon per unit of model output.

As an example, the vector of intensities for China in G-Cubed is shown in Table B.1. Note that the coefficients for sectors $2-6$ are omitted because they are fossil fuels and imports are taxed directly (no need for border adjustments). Coefficients for

Table B.1. Carbon intensity coefficients for China in G-Cubed.

\begin{tabular}{lc}
\hline Sector $j$ & $c_{R i}$, mmt C per unit of output \\
\hline 7 & 0.00038 \\
8 & 0.00010 \\
9 & 0.00011 \\
10 & 0.00013 \\
11 & 0.00042 \\
12 & 0.00004 \\
\hline
\end{tabular}


sectors 1 and 13-20 are also omitted since they are delivered or generated electricity and are essentially non-traded.

\section{Step 2: Construct BCAs}

Now suppose that country A imposes carbon tax $\mathrm{TCAR}_{A}$ on domestic production and imports of fossil fuels, and that country B does not have a similar tax. If A wants to impose a border carbon tax on imports from country B it would like to charge the following on good $j$ imported to A from B:

$$
\mathrm{BCT}_{A B j}=c_{B i} \mathrm{TCAR}_{A} \text {. }
$$

\section{Step 3: Compute revenue from BCAs}

The externality revenue in destination country $A$ is increased by the following, where $j$ ranges over traded goods and $B$ ranges over countries of origin:

$$
\sum_{j} \sum_{B} \mathrm{BCT}_{A B j} \mathrm{IMP}_{j A B} \text {. }
$$

An equivalent computation that may be more convenient for some purposes would be to compute the total embodied carbon in imports by country $A$ (denoted $\mathrm{ECAR}_{A}$ ) and then multiply by the tax:

$$
\mathrm{ECAR}_{A}=\sum_{j} \sum_{B} c_{B j} \mathrm{IMP}_{j A B} .
$$

The revenue is then:

$$
\mathrm{TCAR}_{A} \mathrm{ECAR}_{A}
$$

\section{References}

Aldy, JE and P William (2009). The Competitiveness Impacts of Climate Change Mitigation Policies. Arlington, VA: Center for Climate and Energy Solutions. Available at: http://www. c2es.org/docUploads/competitiveness-impacts-report.pdf.

Böhringer, C, J Carbone and T Rutherford (2012). Unilateral climate policy design: Efficiency and equity implications of alternative instruments to reduce carbon leakage. Energy Economics: Supplement 2, 34, S208-S217. Available at: http://dx.doi.org/10.1016/j. eneco.2012.09.011.

Branger, F and P Quirion (2014). Would border carbon adjustments prevent carbon leakage and heavy industry competitiveness losses? Insights from a meta-analysis of recent economic studies. Ecological Economics, 99, 29-39. Available at: http://dx.doi.org/10.1016/j.ecolecon.2013.12.010.

Congressional Budget Office (2011). Reducing the Deficit: Spending and Revenue Options. Washington, DC: Congressional Budget Office. Available at: http://www.cbo.gov/publication/22043.

Congressional Budget Office (2013). Border Adjustments for Economy-wide Policies That Impose a Price on Greenhouse Gas Emissions. Washington, DC: Congressional Budget Office. Available at: https://www.cbo.gov/sites/default/files/113th-congress-2013-2014/ reports/44971-GHGandTrade.pdf. 
Condon, M and A Ignaciuk (2013). Border Carbon Adjustment and International Trade: A Literature Review. Paris: Organization for Economic Cooperation and Development Trade and Environment Working Papers. Available at: http://dx.doi.org/10.1787/5k3xn25b386c-en.

Cosbey, A (2008). Border Carbon Adjustment. Winnipeg: International Institute for Sustainable Development. Available at: https://www.iisd.org/pdf/2008/cph_trade_climate_border_ carbon.pdf.

Elmendorf, DW (2009). Statement to the U.S. Senate Committee on Finance. In The Distribution of Revenues from a Cap-and-Trade Program for CO2 Emissions: Hearing Before the Committee on Finance, 3rd Cong., 1st session, May 7, 2009. Washington: U.S. G.P.O. Available at: https://www.cbo.gov/sites/default/files/111th-congress-2009-2010/reports/0507-cap_and_trade_testimony.pdf.

Fischer, C and AK Fox (2012a). Climate policy and fiscal constraints: Do tax interactions outweigh carbon leakage? Energy Economics: Supplement 2, 34, S218-S227. Available at: http://dx.doi.org/10.1016/j.eneco.2012.09.004.

Fischer, C and AK Fox (2012b). Comparing policies to combat emissions leakage: Border tax adjustments versus rebates. Journal of Environmental Economics and Management, 64(2), 199-216. Available at: http://dx.doi.org/10.2139/ssrn.1345928.

Fischer, C, R Morgenstern and N Richardson (2015). Carbon taxes and energy-intensive tradeexposed industries. In Implementing A US Carbon Tax, Ian Parry, AC Morris and RC Williams III (eds.), pp. 159-177, New York: Routledge.

Goulder, LH (1995). Environmental taxation and the double taxation: A reader's guide. International Tax and Public Finance, 2(2), 157-183. Available at: http://dx.doi.org/ 10.1007/BF00877495.

Jorgenson, DW, RJ Goettle, MS Ho and PJ Wilcoxen (2013). Double Dividend: Environmental Taxes and Fiscal Reform in the United States. MIT Press. Available at: https://doi.org/ 10.7551/mitpress/9780262027090.001.0001.

Jorgenson, DW, RJ Goettle, MS Ho and PJ Wilcoxen (2015). Carbon taxes and fiscal reform in the United States. National Tax Journal, 68(1), 121-138. Available at: http://dx.doi.org/ 10.17310/ntj.2015.1.05.

Kortum, SS and DA Weisbach (2017). The design of border adjustments to carbon prices. National Tax Journal, 70(2), 421-446, Working paper. Available at: http://www.rff.org/files/ document/file/RFF-DP-16-09.pdf.

McKibbin, WJ, AC Morris and PJ Wilcoxen (2012a). Pricing carbon in the United States: A model-based analysis of power sector only approaches. Resource and Energy Economics, 36, 130-150. Available at: http://www.brookings.edu/ /media/research/files/papers/2012/ 10/05-pricing-carbon-morris/05-pricingcarbon-morris.pdf.

McKibbin, WJ, AC Morris, PJ Wilcoxen and Y Cai (2012b). The Potential Role of a Carbon Tax in U.S. Fiscal Reform, Climate and Energy Economics Discussion Paper. Washington, DC: Brookings Institution. Available at: https://www.brookings.edu/wp-content/uploads/ 2016/06/carbon-tax-mckibbin-morris-wilcoxen.pdf.

McKibbin, WJ, AC Morris, PJ Wilcoxen and Y Cai (2015). Carbon taxes and U.S. fiscal reform. The National Tax Journal, 68(1), 139-156. Available at: http://dx.doi.org/10.17310/ ntj.2015.1.06.

McKibbin, WJ, D Pearce and A Stegman (2009). Climate change scenarios and long term projections. Climate Change, 97(1), 23-47. Available at: http://dx.doi.org/10.1007/s10584009-9621-3.

McKibbin, WJ and PJ Wilcoxen (1999). The theoretical and empirical structure of the G-Cubed model. Economic Modelling, 16(1), 123-148. Available at: https://www.brookings.edu/wpcontent/uploads/2016/06/bdp118.pdf. 
McKibbin, WJ and PJ Wilcoxen (2009). The economic and environmental effects of border tax adjustments for climate policy. In Climate Change, Trade and Competitiveness, L Brainerd and I Sorkin (eds.), pp. 1-34. The Brookings Institution.

McKibbin, WJ and PJ Wilcoxen (2013). A global approach to energy and environment: The G-Cubed model. In Handbook of Computable General Equilibrium Modeling, pp. 995-1068, Elsevier.

OECD (2016). Effective Carbon Rates: Pricing $\mathrm{CO}_{2}$ Through Taxes and Emissions Trading Systems, Paris: OECD Publishing. Available at: http://www.keepeek.com/Digital-AssetManagement/oecd/taxation/effective-carbon-rates_9789264260115-en\#.Wk1D4vlSypo\# page1.

Parry, IWH, C Veung and D Heine (2015). How much carbon pricing is in. countries' own interests? The critical role of co-benefits. Climate Change Economics, 06, 04.

Parry, I and R Williams (2012). Moving US climate policy forward: Are carbon taxes the only good alternative? In Climate Change and Common Sense: Essays in Honour of Tom Schelling, R Hahn and A Ulph (eds.). Oxford University Press. Available at: http://www. oxfordscholarship.com/view/10.1093/acprof:oso/9780199692873.001.0001/acprof9780199692873-chapter-10.

Rausch, S and J Reilly (2015). Carbon taxes, deficits, and energy policy interactions. National Tax Journal, 68(1), 157-178. Available at: http://dx.doi.org/10.17310/ntj.2015.1.07.

Sakai, M and J Barrett (2016). Border carbon adjustments: Addressing emissions embodied in trade. Energy Policy, 92, 102-110. Available at: http://dx.doi.org/10.1016/j.enpol.2016. 01.038 .

Trachtman, JP (2016). WTO law constraints on border tax adjustment and tax credit mechanisms to reduce the competitive effects of carbon taxes. Discussion Paper RFF DP 1603. Washington, DC: Resources for the Future. Available at: http://www.rff.org/research/ publications/wto-law-constraints-border-taxadjustment-and-tax-credit-mechanisms-reduce.

Tuladhar, SD, WD Montgomery and N Kaufman (2015). Environmental policy for fiscal reform: Can a carbon tax play a role?" National Tax Journal, 68(1), 179-194. Available at: http://dx.doi.org/10.17310/ntj.2015.1.08.

World Bank, Ecofys and Vivid Economics (2017). State and Trends of Carbon Pricing 2017 (November). Washington, DC: World Bank. Available at: https://openknowledge.worldbank.org/bitstream/handle/10986/28510/wb_report_171027.pdf?sequence=5\&isAllowed=y. 